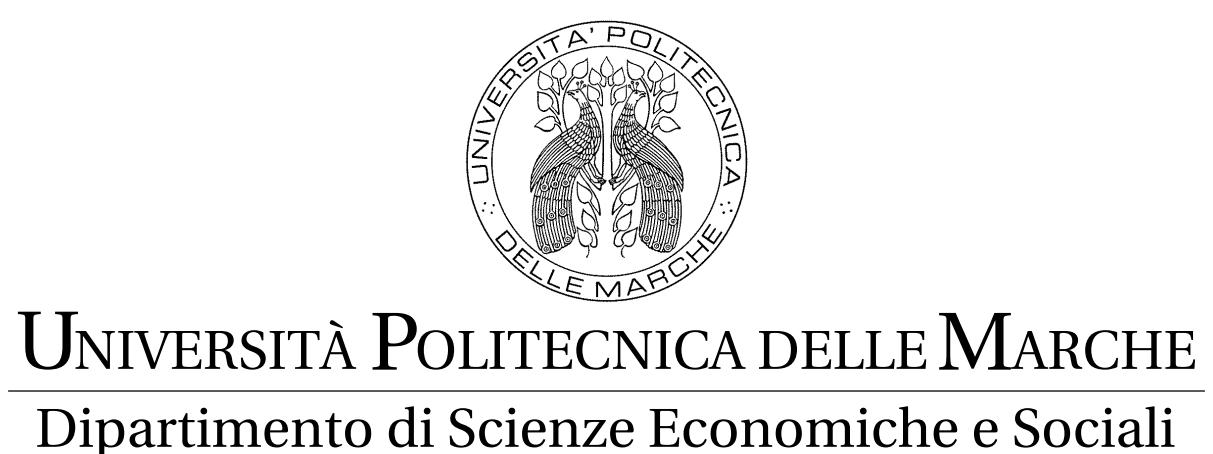

\title{
DOES APPRENTICESHIP IMPROVE JOB OPPORTUNITIES? A REGRESSION DiSCONTINUITY APPROACH
}

Matteo Picchio and Stefano Staffolani

QUADERNI DI RICERCA n. 393*

November 2013

(*) La numerazione progressiva continua dalla serie denominata "Quaderni di ricerca — Dipartimento di economia" 
Comitato scientifico:

Renato Balducci

Marco Gallegati

Alberto Niccoli

Alberto Zazzaro

Collana curata da Massimo Tamberi

ISSN: 2279-9575 
JEL Class.: $\quad$ C36, C41, J24, J41

Keywords: Apprenticeship, temporary work, permanent work, regression discontinuity, hazard function

Indirizzo: Matteo Picchio, Corresponding author. Department of Economics and Social Sciences, Marche Polytechnic University; CentER, Tilburg University; Sherppa, Ghent University; IZA, Bonn. E-mail: m.picchio@univpm.it. Tel.: +39 0712207176.

Stefano Staffolani, Department of Economics and Social Sciences, Marche Polytechnic University. E-mail: s.staffolani@univpm.it. Tel.: +39071220 7090. 



\title{
Does Apprenticeship Improve Job Opportuni- ties? A Regression Discontinuity Approach*
}

\author{
Matteo Picchio and Stefano Staffolani
}

\section{Introduction}

In the last decades, employment security has been widely studied in the economic literature because of the growing share of youth either unemployed or employed on temporary basis in Europe. Since the end of the 1980s, the labour market institutions have indeed changed and the use of temporary contracts have been eased in many OECD countries, amongst which Italy. According to Eurostat data (http://epp.eurostat.ec.europa.eu), in the period 1998-2012, the share of employees between 15 and 24 years of age with a temporary contract rose from $37.8 \%$ to $42.8 \%$ in the European Union (15 members). In Italy, the same figure moved instead from $23.4 \%$ to $53.4 \%$. Policy makers often see in temporary contracts an instrument to improve the capability of the economy to adapt to changing conditions and to a rising international competition (OECD, 1996).

The growing share of temporary employees has risen doubts and concerns about the possible effects on workers' short-term and long-term perspectives. If employment protection of permanent workers is strict and firing costs are high, disadvantaged groups (youth, women and long-term unemployed) might be excluded from employment. Firms would attribute indeed more importance to the assessment of workers' quality when employment protection is strict ${ }^{1}$ and disadvantaged individuals may benefit most from the

*The Compulsory Communication Data are used with the permission of the Ministry of Labour and Social Policies thanks to the agreement between the Department of Economics and Social Sciences of Marche Polytechnic University and General Department for the Innovation Technology of the Ministry of Labour and Social Policies. We also wish to thank Massimiliano Bratti and the participants to the AIEL Conference in Rome (September 2013).

${ }^{1}$ Faccini (2013) presents a theoretical model embedding the screening hypothesis and explaining why the screening device of temporary jobs is more important in economies with higher firing costs of permanent employees. Boockmann and Hagen (2008) find empirical evidence supporting the role of fixed-term contracts as screening periods in West Germany, with bad matches dissolved earlier than under high firing 
increased flexibility and availability of temporary jobs. Temporary jobs can be screening devices giving a chance to disadvantaged workers to enter the labour market. However, if the labour market is segmented with large firing costs of permanent workers, firms might use temporary jobs just as a buffer to face cyclical downturns. ${ }^{2}$ Job security, on-the-job training, and lifelong earnings are thereby some of the dimensions of job quality which might be at stake.

Although economic theories provide ambiguous predictions on whether temporary jobs might be a port of entry into permanent positions or dead end jobs, the empirical evidence for the European labour market is more clearcut. In Belgium, Germany, Italy, the Netherlands, Sweden, and the UK, researchers find that temporary jobs are stepping stones into permanent jobs. ${ }^{3}$ In contrast, de Graaf-Zijl (2005) and Amuedo-Dorantes et al. (2009) report that the port of entry hypothesis does not hold in Spain. As pointed out by Cockx and Picchio (2012), institutions might explain this dissonant result: Spain has one of the strictest employment protection legislation for permanent workers in the EU (OECD, 2004) and the use of temporary jobs as a flexibility buffer might thereby dominates its use as a screening device.

In some countries, it is possible to identify different types of temporary contracts: for example a worker might be linked to a firm on a temporary basis via a fixed-term contract, a temporary-work-agency (TWA), or an apprenticeship. Different forms of temporary arrangements might imply different ways in which workers are treated, especially with respect to the amount of training provided by the employer. The economic theory does not offer clearcut predictions about the relation between the type of job arrangement and the incentives of firms to invest in training. On the one hand, firms' incentives to invest in training are negatively related to the probability of a job mismatch (see, e.g., Acemoglu and Pischke, 1998). If the expected duration of the employer-employee match of a particular type of temporary contract (e.g. seasonal jobs, on-call jobs, TWA jobs) is shorter than others, the probability of recouping the training investment is lower and firms will be less likely to provide training to workers with such arrangements. On the other hand, since training, in addition to fostering human capital, induces self-selection of more able workers and facilitates worker screening (Autor, 2001), firms might be willing costs.

${ }^{2}$ See Casquel and Cunyat (2008) for a theoretical model which links firing costs and unemployment benefits to the conversion rates into permanent contracts.

${ }^{3}$ See Booth et al. (2002b), Hagen (2003), Göbel and Verhofstadt (2008), Ichino et al. (2008), Picchio (2008), Hartman et al. (2010), Berton et al. (2011), and de Graaf-Zijl et al. (2011). Cockx and Picchio (2012) finds that in Belgium even a job experience lasting no more than three months is able to increase the job stability of young unemployed school-leavers. 
to provide temporary workers with training before locking themselves in an open-ended job relationship. ${ }^{4}$ Another form of temporary contractual arrangement characterized by a particular treatment of the worker with respect to the amount of firm-provided training is the apprenticeship. For example, in Germany and Italy firms are entitled to a reduction in the labour taxes for the workers hired with an apprenticeship contract. However, they are obliged to invest in the human capital of their apprentices by providing them with training. 5

The availability of different types of temporary contracts provides firms with more flexibility in choosing the arrangement that fits better with their labour force needs. In Italy, a firm might prefer the apprenticeship to other forms of temporary contracts for instance when it needs to save in labour costs, in terms of both labour taxes and lower wage rates. Labour cost savings might be however offset by the expenditures in training to comply with the Italian regulations. Nonetheless, as the abilities and skills of young workers are in general unknown, a job contract characterized by lower wages but firm-provided training might allow firms to select the most motivated and career oriented workers. A firm might instead prefer to hire workers on the basis of fixed-term contracts or via a TWA when it is needed to screen workers' abilities before providing them with training, for example, when training is too costly, or when the economy is very unstable and therefore firms do not have a incentives to invest in workers' training. ${ }^{6}$

In view of the current economic situation and the high level of youth unemployment, in the last years the political debate has been increasingly looking at the apprenticeship as one of the main channels of labour market entry for youth between 18 and 29 years of age. After the reforms in 1997 (Law No. 196/1997) and 2003 (Law No. 30/2003) which made easier the use of different forms of temporary contracts, among which the apprenticeship, Legislative Decree No. 167/2011 and Law No. 92/2012 have indeed highly regulated the use of apprenticeship and defined it as a job relationship with the special aim of fostering human capital. Moreover, the most recent discipline has extended

${ }^{4}$ Autor (2001) proposes and tests a model for the US in which temporary-work-agencies provide workers also general human capital and are able to attract higher ability workers yet paying them lower wages after training.

${ }^{5}$ In Italy, apprenticeship is regulated by Law No. 196/1997 and by Law No. 276/2003 at the central level, but many characteristics of the contract are delegated to territorial authorities and collective bargaining. The length of the apprenticeship contract cannot generally be shorter than six months and longer than three years. If the firm does not comply with the requirement of providing the apprentice with training, it is fined. Other information on the apprenticeship contract are available at: www.wikilabour.it/Apprendistato.ashx.

${ }^{6}$ See Askilden and Nilsen (2005) for an empirical test on the link between the business cycle and apprenticeship in Norway. 
it also to high-skill workers, made it clear that the firm must provide the apprentices with the necessary training to perform their job tasks, included apprenticeship contracts among those bargained on by national unions, and made it as an eventual tool to reduce the mismatch between labour demand and supply by allowing the apprentice to get an educational diploma at the end of the training period.

Given this renewed interest of the policy maker in apprenticeship and since there is no well-established path from school to work in Italy, it is policy relevant to understand whether the apprenticeship might be able to play a role as a port of entry into stable jobs, especially in a period of severe economic crisis and exploding youth unemployment. The main contribution of this article consists thereby in evaluating whether apprenticeships are effective pathways into permanent jobs compared to other forms of temporary jobs. More in detail, we take a sample of young workers starting a temporary job in 2009 and we follow them over time until they enter a permanent job. We estimate the hazard function of entering a permanent job of temporary workers with and without an apprenticeship contract.

Whether an individual enters the labour market through an apprenticeship contract or another type of temporary job is a potentially endogenous variable: there might be unobserved characteristics at individual and firm levels which are related both to the probability of entering the labour market as an apprentice (rather than with another type of temporary job) and to the duration until a permanent job. Ability, motivation, labour force attachment, human capital, previous labour market experiences, and firm hiring strategy are examples of such unobserved characteristics. We exploit discontinuities in the probability of entering the labour market with an apprenticeship contract exogenously generated by the institutional setting to identify the effect of the contract type on the hazard function towards a permanent job without having to rely on exclusion restrictions or parametric assumptions. In our application, the assignment to apprenticeship is indeed partly determined by whether the forcing variable, age, crosses some cutoff points. Once individuals turn 25 years old (27 years old in some regions), the types of allowed apprenticeship contracts are reduced by law: workers can still be hired as apprentices but with a limited number of possible apprenticeship contracts; once people turn 30 years old, they cannot be hired any longer as apprentices.

Despite several studies have been conducted on the impact of temporary employment on several dimensions of employment quality like earnings, unemployment exit rate, probability of finding a permanent job, safety at work, and employment stability, ${ }^{7}$ the em-

\footnotetext{
${ }^{7}$ See, e.g., Booth et al. (2002a) and the related special issue on temporary employment.
} 
pirical literature on the effect of apprenticeship on the subsequent working career is scarce and mostly based on non-experimental approaches. We contribute to the empirical literature on temporary jobs and youth labour market by identifying, in a quasi-experiment setting and exploiting exogenous information generated by the institutional set-up, the difference between the apprenticeship and other types of temporary contracts in making youth transit towards an open-ended job relationship.

We find that two years after the beginning of the apprenticeship, apprentices have a higher propensity to get a permanent position than those who entered the labour market through other forms of temporary jobs. In a second step of the analysis, we distinguish between the transition to a permanent contract for the same firm providing the initial temporary position and for a different firm. We find that the probability of getting a permanent job within the same firm is strongly higher for apprentices (especially three years after the treatment). The hazard function towards a permanent job within a different firm is instead higher for workers having other types of temporary positions. We interpret this finding as apprentices accumulating more specific skills and less general human capital than workers with other types of temporary positions.

This paper is organised as follows. Section 2 reviews the related empirical literature. Section 3 describes the institutional setting of the Italian labour market and the dataset used in the empirical analysis. Section 4 explains how we identify the difference between apprenticeship and other forms of temporary jobs in allowing workers to access a permanent job. In Section 5 we report and comment on the estimation results. Section 6 concludes.

\section{Related Literature}

The existing empirical studies on the impact of apprenticeship on future labour market career is scarce. A first analysis was conducted by Booth and Satchell (1993) in the UK. They find that completed apprenticeships decrease the probability of a job separation, suggesting that both employers and apprenticed youths wished to continue the employment relationship: involuntary layoffs and voluntary quits were reduced by completed apprenticeships. Clark and Fahr (2002), using a large German administrative dataset, find that the wage returns to apprenticeship are comparable to standard estimates of the returns to school and that the training received during the apprenticeship period is transferable across a wide range of occupations. Gambin et al. (2011) made an up-to-date review of many aspects concerning apprenticeship: theoretical and empirical models to evaluate 
its long-term impact, but also the advantages and disadvantages of administrative dataset versus surveys data or qualitative dataset.

The Italian labour market is characterized by several contract types (more than 50 at the time of writing). Researchers have therefore devoted some attention to the understanding of the link between the contract type and the subsequent labour market career. Berton et al. (2011) studied the impact of different types of contracts on the probability of finding a permanent job. They exploit administrative data for the period 1994-2004 and estimate dynamic multinomial logit models with fixed effects to allow for the non-random sorting of workers into different types of contracts. They conclude that temporary jobs are a port of entry towards permanent employment, but the estimated effect is found to be heterogeneous across contract types. Training contracts ${ }^{8}$ seem to be the best port of entry into permanent employment, followed by fixed-term contracts, apprenticeships (as defined by the old regulation), and, at the bottom, freelance work. Although the empirical analysis exploits multiple observations per individual to solve the selection on unobservables into the contract type, Berton et al.'s (2011) model is not able to take into account time-varying covariates and the identification of the causal link is based on parametric assumptions.

Bosio (2011) presents a duration dependence analysis in order to evaluate to what extent temporary contracts are a stepping stone towards permanent jobs in Italy in the period 1992-2002. He finds that the probability of moving to a permanent job depends on the type of temporary job: after the 1997 labour market reform, TWA jobs and apprenticeships exhibit lower transition rates towards a permanent job than the ones of other forms of temporary jobs. The analysis in this study contains however the drawback that the selection into the type of contract is assumed to be exogenous.

Cappellari et al. (2012) evaluate the effect of the 2001 and 2003 labour market reforms ${ }^{9}$ on how firm use fixed-term and apprenticeship contracts. They identify the effect exploiting the fact that the implementation of the reform was at different times across regions. They find that the 2003 reform of apprenticeship increased job turnover and the substitution of external staff with apprentices, with a positive effect on productivity. The 2001 reform of fixed-term contracts induced instead a substitution of temporary employees with external staff. Therefore, the recent labour market reforms may have made the

\footnotetext{
${ }^{8}$ Under the current legislation, the training contracts are no longer allowed. The training contracts were similar to the current apprenticeship contract: employers benefited a labour cost reduction but had to provide formal training.

${ }^{9}$ The 2001 labour market reform was implemented by Legislative Decree No. 368/2001. In a nutshell, it eased the use of fixed-term contracts.
} 
apprenticeship preferable by reducing its costs and by increasing the costs of fixed-term contracts.

Finally, Lilla and Staffolani (2012) analyse youth probability of getting a permanent position entering the labour market with different types of temporary contracts. They find that the probability of obtaining a permanent job is higher for apprentices, freelances, interim workers than the one of workers with a fixed-term contract. However, they also show that apprentices have the highest probability of experiencing a job interruption before the scheduled expiry date. As in Bosio (2011), Lilla and Staffolani (2012) do not attempt to solve the problem of workers' selection a on unobservables into different types of contracts.

\section{Data and Sample}

All Italian private companies and the public administrations are obliged to communicate hirings, prolongations, transformations, and cessations of labour contracts to the local labour offices. The Ministry of labour, health, and social policies collects the data coming from labour offices and builds the Compulsory Communication Database (CCD). From this database, the Ministry selected a sample of workers born on four specific days of the year: March 15, June 15, September 15, and December 15. Hence, the sample contains about 1 out of 91 of all workers who started, changed, or ceased a labour relationship. ${ }^{10}$ The dataset covers the time window going from the beginning of January 2009 until the end of June 2012.

The unit of observation in the database is the single contract. The database contains 411, 964 contracts started between the beginning of January 2009 until the end of June 2012, referring to 141,363 single workers. For each contract, we have information about firm location, firm sector, worker's educational attainment, gender, nationality, and residence. We also know the main characteristics of the contract arrangement: the type of contract, national collective agreement, sector, required worker's qualification, and working time (part-time versus full-time).

In Italy, besides the permanent contract which is still the standard arrangement, there are 41 types of temporary contracts. In our empirical analysis, we group them in two main categories:

\footnotetext{
${ }^{10}$ The CCD exists in Italy since a long time, but until 31/12/2007 firms had to send the required forms by post. Since 01/01/2008, firms are obliged to access to the information system in Internet at the web-address http://www.co.lavoro.gov.it. Data collected in 2008 are affected by problems of misreporting and cannot be used for empirical analyses.
} 
- Apprenticeship contracts for which training provided by the employer is mandatory. Apprenticeship contracts are ruled by Law No. 196/1997 and Law No. 276/2003. There are three different types of apprenticeships: the "apprenticeship for the completion of the right and the duty of training", the "vocational apprenticeship", and the "apprenticeship aimed at the acquisition of a degree". The employer must define the qualification that the worker will acquire during the apprenticeship period and must accordingly provide her with training. The employer benefits from a reduction in apprentices' labour taxes. Furthermore, apprentices can be hired at a lower level of professional classification with respect to regular workers performing the same tasks, implying a lower wage. No minimum duration of the apprenticeship contract is required by law.

- Temporary contracts, which comprises all the forms of temporary work, like fixedterm contracts, TWA jobs, on-call jobs, seasonal jobs, and on-projects jobs. We do not include into this category internships, as interns are not salaried workers. Individuals entering the labour market through an internship are removed from our sample (about $3 \%$ of the original sample).

We keep only workers who in 2009 are between 18 and 35 years old and entered the labour market with a temporary or an apprenticeship contract. By limiting the analysis to a sample of fresh job spells started in 2009, we avoid problems of left-censoring and we have a long enough observation period before the end of the observed time window (June 30 2012). We drop workers who had more than 20 contracts in the whole period of observation (about $1 \%$ of the sample). After applying these selction criteria, we end up with an inflow sample into temporary or apprenticeship contracts of 22,207 individuals.

In this study we are interested in the time until the worker is able to transit from either a temporary or an apprenticeship contract to a permanent position. Figure 1 and Table 1 report descriptive statistics of the outcome variable of this study, i.e. time until a permanent job. Figure 1 displays the smoothed (rectangle kernel function) Kaplan-Meier hazard functions by contract type. During the first year since sample entry, temporary workers enjoy an higher probability of finding a permanent job. In the second year apprentices and temporary workers share very similar hazard rates. From that moment onward, apprentices show instead a higher probability of finding a permanent job. The time horizon we can study is not long and most workers who flowed into our sample in 2009 have not found a permanent job yet by the end of our time window. Table 1 shows indeed that more than $70 \%$ of the spells are not completed by June 30 2012. In analysing durations, 
this calls for econometric methods that are able to deal with right censored observations. Given the large fraction of right censored spells, the mean but also the median are biased downwards. If we look at the 25 th percentile of the duration distribution, it seems that individuals with a temporary contract are able to find a permanent job faster: the 25 th percentile is 840 days against 954 days of apprentices. This difference might be due to a true positive effect of temporary jobs when contrasted to apprenticeships. However, the effect might be spurious and due to the fact that individuals might select themselves into the type of contract on the basis of observable characteristics but also on the basis of characteristics that are unobservable to the analyst. In Section 4, we explain how we control for observed characteristics and how we deal with the selection on unoservables.

Figure 1: Smoothed Kaplan-Meier permanent job hazard function by contract type
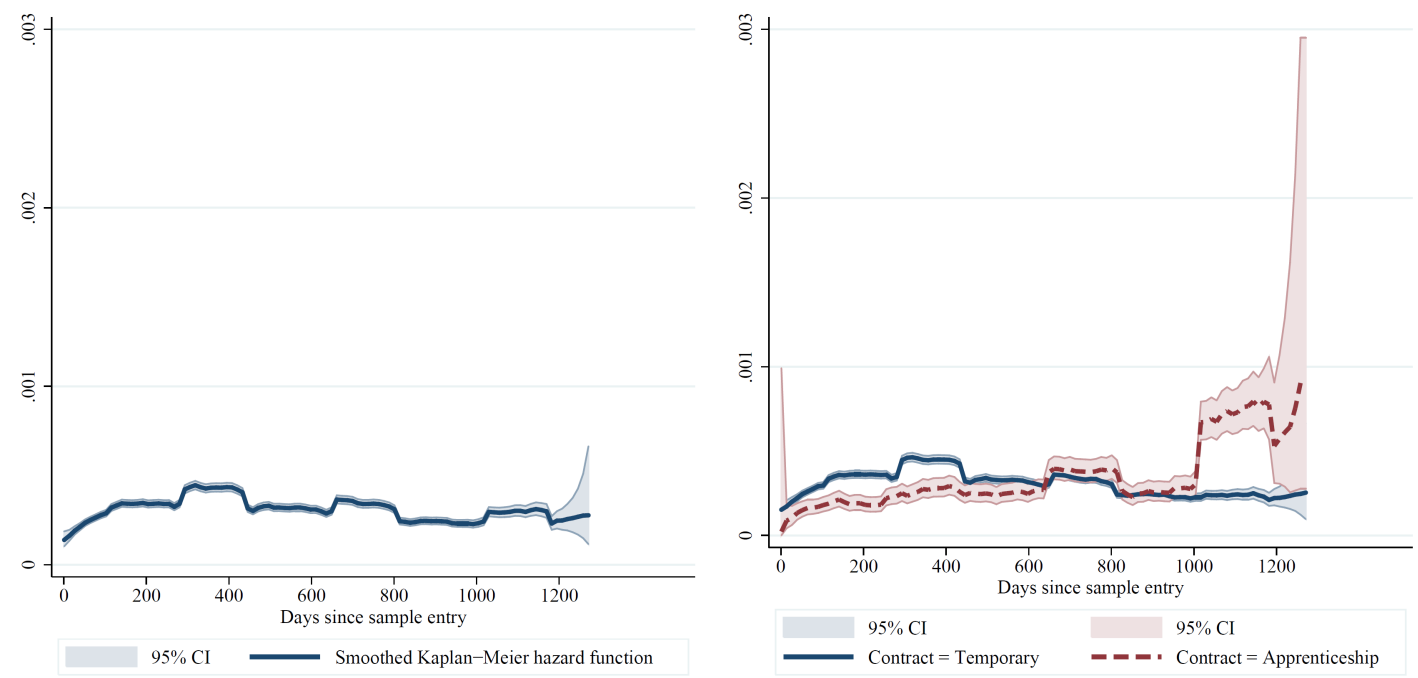

Table 1: Summary statistics of spell durations until a permanent job by contract type

\begin{tabular}{lccc}
\hline \hline & Full sample & Temporary jobs & Apprenticeships \\
\hline Total observed spells & 22,207 & 20,011 & 2,196 \\
Average spell duration until permanent job (days) & 935.35 & 930.15 & 982.71 \\
Completed transitions to a permanent job by June 30th, 2012 & 6,588 & 5,947 & 641 \\
Fraction of right censored spells & 0.703 & 0.703 & 0.708 \\
Duration percentiles (days) & & & 73 \\
$\quad$ 1st percentile & 57 & 53 & 288 \\
5th percentile & 182 & 180 & 485 \\
10th percentile & 344 & 333 & 954 \\
25th percentile & 870 & 840 & \\
\hline
\end{tabular}


Table 2 reports summary statistics of the regressors used in the econometric analysis for the full sample and by contract type. About $10 \%$ of workers entered the labour market as apprentices. The youth, males, leaving in center-norther regions (with the exception of Lombardia and Trentino Alto Adige), medium educated and immigrants coming from non-European countries are more likely to start an apprenticeship. Individuals with a university degree or EU immigrants are instead more likely to start a temporary job.

Table 2: Summary statistics of covariates by contract type

\begin{tabular}{|c|c|c|c|c|c|c|}
\hline & \multicolumn{2}{|c|}{ Full sample } & \multicolumn{2}{|c|}{ Temporary jobs } & \multicolumn{2}{|c|}{ Apprenticeships } \\
\hline & Mean & Std. Dev. & Mean & Std. Dev. & Mean & Std. Dev. \\
\hline Apprenticeship & 0.099 & 0.299 & - & - & - & - \\
\hline Age (in days) & $9,665.3$ & $1,755.2$ & $9,826.6$ & $1,737.2$ & $8,195.1$ & $1,120.1$ \\
\hline Female & 0.493 & 0.500 & 0.500 & 0.500 & 0.428 & 0.495 \\
\hline Regional unemployment rate ${ }^{\S}$ & 0.078 & 0.035 & 0.079 & 0.035 & 0.068 & 0.031 \\
\hline \multicolumn{7}{|l|}{ Education } \\
\hline None or primary & 0.194 & 0.395 & 0.199 & 0.399 & 0.144 & 0.351 \\
\hline Lower secondary & 0.330 & 0.470 & 0.325 & 0.468 & 0.380 & 0.486 \\
\hline Higher secondary & 0.358 & 0.479 & 0.350 & 0.477 & 0.431 & 0.495 \\
\hline University or more & 0.118 & 0.323 & 0.126 & 0.332 & 0.045 & 0.207 \\
\hline \multicolumn{7}{|l|}{ Region } \\
\hline Piemonte-Valle d'Aosta & 0.065 & 0.247 & 0.063 & 0.242 & 0.089 & 0.285 \\
\hline Lombardia & 0.146 & 0.353 & 0.147 & 0.354 & 0.140 & 0.347 \\
\hline Trentino Alto Adige & 0.038 & 0.191 & 0.039 & 0.194 & 0.026 & 0.160 \\
\hline Veneto & 0.076 & 0.265 & 0.071 & 0.257 & 0.119 & 0.324 \\
\hline Friuli Venezia Giulia & 0.021 & 0.142 & 0.020 & 0.140 & 0.026 & 0.160 \\
\hline Liguria & 0.026 & 0.160 & 0.023 & 0.150 & 0.054 & 0.226 \\
\hline Emilia Romagna & 0.098 & 0.297 & 0.097 & 0.296 & 0.102 & 0.303 \\
\hline Toscana & 0.067 & 0.250 & 0.063 & 0.243 & 0.099 & 0.299 \\
\hline Umbria & 0.016 & 0.127 & 0.016 & 0.124 & 0.025 & 0.155 \\
\hline Marche & 0.028 & 0.164 & 0.026 & 0.160 & 0.041 & 0.199 \\
\hline Lazio & 0.102 & 0.303 & 0.104 & 0.305 & 0.087 & 0.281 \\
\hline Abruzzo-Molise & 0.029 & 0.167 & 0.028 & 0.166 & 0.031 & 0.173 \\
\hline Campania & 0.064 & 0.245 & 0.068 & 0.251 & 0.030 & 0.170 \\
\hline Puglia & 0.069 & 0.254 & 0.071 & 0.257 & 0.050 & 0.218 \\
\hline Basilicata-Calabria & 0.049 & 0.215 & 0.052 & 0.222 & 0.020 & 0.139 \\
\hline Sicilia-Sardegna & 0.106 & 0.308 & 0.111 & 0.314 & 0.061 & 0.239 \\
\hline \multicolumn{7}{|l|}{ Nationality } \\
\hline Italian & 0.790 & 0.407 & 0.789 & 0.408 & 0.800 & 0.400 \\
\hline EU & 0.099 & 0.298 & 0.102 & 0.302 & 0.069 & 0.254 \\
\hline Non EU & 0.111 & 0.314 & 0.109 & 0.311 & 0.131 & 0.338 \\
\hline Observations & \multicolumn{2}{|c|}{22,207} & \multicolumn{2}{|c|}{20,011} & \multicolumn{2}{|c|}{2,196} \\
\hline
\end{tabular}




\section{The Regression Discontinuity Approach}

\subsection{Graphical Analysis}

This empirical analysis is aimed at identifying the impact of the type of contract at labour market entrance on the probability of finding a permanent job. We distinguish between apprenticeship contracts and temporary contracts. The type of contract cannot easily be assumed to be an exogenous variable. It is very likely to be correlated with a set of individual characteristics unobserved by the analyst, like ability, labour market attachment, motivations, human capital, and previous labour market experiences which also determine the outcome variable, i.e. the time needed since labour market entry to get promoted to an open-ended contract. Identification is based on the discontinuity in the propensity to be hired as an apprentice with respect to a forcing variable, age in this study, at some cutoff points. The institutional setting imposes some constraints on the possibility to be hired as an apprentice. Generally, individuals can be hired as apprentices if they are younger than 29 years and 364 days. There also some particular forms of apprenticeship which are only allowed until 24 years and 364 days of age; this age threshold is set to 26 years and 364 days in Campania, Puglia, Basilicata, Calabria, Sicilia, and Sardegna because of the state of the labour market in these regions. In Italy there are no such age rules for the hiring of workers on temporary basis. Hence, we know, at least in part, the mechanism through which individuals are assigned to an apprenticeship contract rather than to a temporary one.

The left panel of Figure 2 displays the propensity to start a job in 2009 with an apprenticeship contract, rather than a temporary one, across the selection variable, age in days. The right panel shows instead the discontinuity in the probability of finding a permanent job by the end of June 2012. These probabilities are predicted by estimating logit models with the following regressors: age, gender, education, region, nationality, regional unemployment rate at sample entry, and the discontinuity dummies at 25-27 years of age and at 30 years of age. The dark curves are fractional-polynomial (degree 2) fits of the predicted probabilities. The left panel of the figure suggests that the institutional setting induces a discontinuity in the relationship between the assignment to apprenticeship and age at labour market entry. When people turn 30 years old, the probability of entering the labour market with an apprenticeship contract jumps to almost zero. In addition, the age rule for being hired as an apprentice is also correlated with the probability of finding a permanent job before the end of the observed time window. The right panel of Figure 2 shows that, after controlling for possible association between a set of regressors, the forcing variable, 
and the probability of getting a permanent contract before the end of the time window, the latter rises with age but it jumps from about $34 \%$ to $28 \%$ at the cutoff point of age equal to 30 years. This suggests a clear link between the discontinuity in the propensity to enter the labour market as an apprentice induced by the institutional setting and the probability of finding a permanent job.

Figure 2: Graphical analysis of the discontinuities
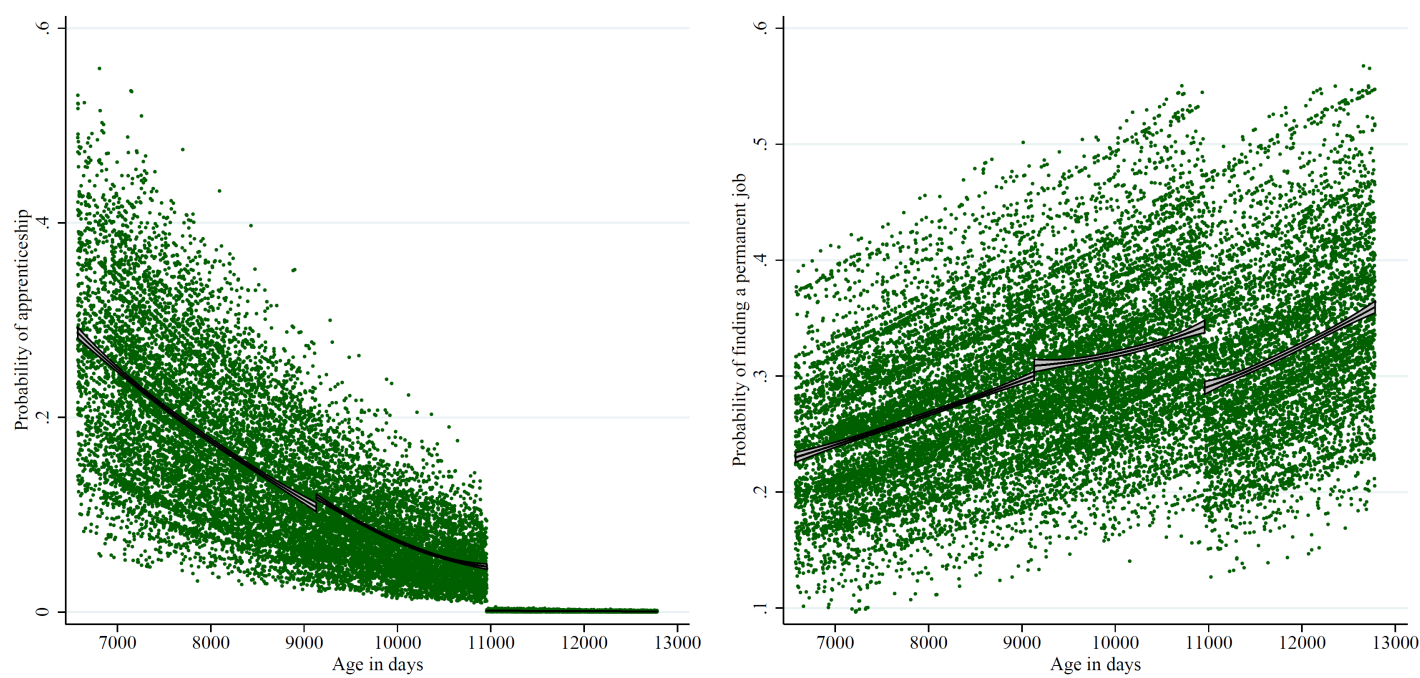

The graphs display predicted probabilities after the estimation of logit models with the following regressors: age, gender, education, region, nationality, regional unemployment rate at sample entry, and the discontinuity dummies at 25-27 years of age and at 30 years of age. The black curves are fractional-polynomial (degree 2) fits of the predicted probabilities along with their 95\% confidence intervals.

However, the discontinuity might also be determined by other unobserved factors. For example, there might be stigmas induced by psychological factors associated with leaving the twenties and turning 30, so that individuals who have not turned into their thirties might be perceived as younger and therefore a better investment for the future. If so, then we should observe a discontinuity in the probability of finding a permanent job with the age at sample entry when focusing only on temporary workers leaving aside the apprentices. Figure 3 reports the fits from fractional-polynomial (degree 2) regressions where the dependent variable is an indicator equal to 1 if the worker moves to a permanent job before the end of the observed time window and 0 otherwise and the independent variable is age at the time of treatment and the constant. We split temporary workers into those younger than 30 and those older than 30 . We run the the fractional-polynomial regression separately for temporary workers younger than 30 and those older than 30 . Figure 3 clearly shows that there are no confounding factors other than the institutional 
setting generating the discontinuity in the probability of finding a permanent job.

Figure 3: Probability of finding a permanent job with respect to age at the time of treatment by contract type

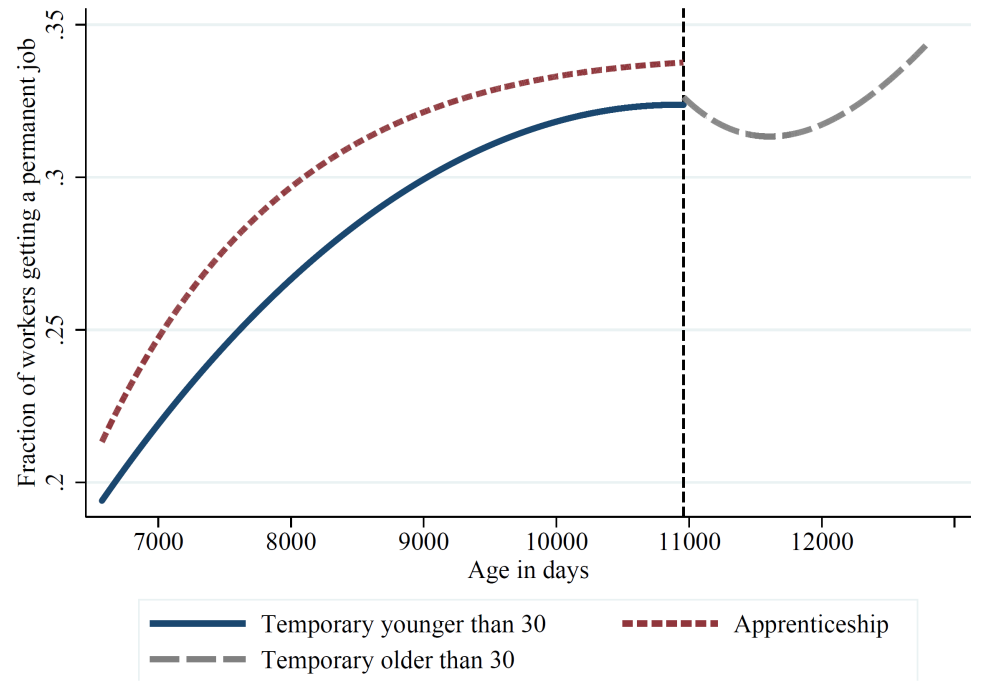

The graph displays the fits from fractional-polynomial (degree 2) regressions where the dependent variable is an indicator equal to 1 if the worker moves to a permanent job before the end of the observed time window and 0 otherwise and the independent variable is age at the time of treatment (sample entry) and the constant Temporary workers are split into those younger than 30 and those older than 30 and the fractional-polynomial regression is separately estimated. The vertical dotted line is the cutoff point at 30 years of age.

\subsection{The Outcome Variable and the Hazard Function}

In Italy, the labour market reforms which took place in the second half of the 1990s and in the first half of the 2000s shaped a dual labour market with different employment protection for regular jobs, i.e. permanent contracts, and temporary atypical arrangements, like apprenticeships and fixed-term jobs. Given the high firing costs that the employer has to pay in case of dismissal of a permanent worker, getting a permanent job in Italy translates into high employment and earning stability. Hence, the outcome variable we will study is the time since the entry in the labour market through an apprenticeship contract or a temporary contract until a permanent job is found.

Apprentices and temporary workers might move with different transition rates towards open-ended contracts. Moreover, the impact of the type of contract on the probability of finding a permanent job might depend on the elapsed duration since the assignment. On the one hand, since the employers have to provide their apprentices with training, 
at the beginning of the employment relation the apprentices might have lower transition rates to permanent jobs than temporary workers, as the apprentices will have interest in completing the training. On the other hand, apprentices might receive more training than temporary workers, and in the medium-long term this might make it easier to transit to a permanent job. Moreover, the two types of contract might be used by firms fir different purposes. For example, temporary jobs might be used just as a buffer to face demand volatility of the final product, whilst apprenticeships might serve as a monitoring and training tool to create high-quality open-end job matches.

We model therefore the hazard function of the duration distribution of the spell starting when the worker leaves non-employment through an apprenticeship or a temporary job and ending when the same worker succeeds in getting a permanent job. We focus on the impact of the initial contract type on the hazard function to a permanent job. The initial contract type is captured by the indicator variable $D_{i}$, which is equal to 1 if individual $i$ entered the labour market as an apprentice and equal to 0 if (s)he entered the labour market with a temporary contract.

The hazard function of moving to a permanent job $t$ days after the labour market entry will be denoted by $\theta\left(t \mid D_{i}, \mathbf{c}_{i}\right)$, where $\mathbf{c}_{i}$ is a set of observed and unobserved factors determining the duration until a permanent job is entered.

\subsection{Fuzzy Regression Discontinuity Design: Identification and Mod- elling}

We are interested in understanding the impact of the contract type at labour market entry on the time until a permanent job is found. The type of contract is however very likely to be endogenous as correlated both with the dependent variable, the duration until a permanent job, and the unobservables. We exploit discontinuities in the probability of entering the labour market with an apprenticeship contract exogenously generated by the institutional setting to identify the effect of the contract type without having to rely on exclusion restrictions or parametric assumptions.

In our application, the assignment to apprenticeship is indeed partly determined by whether the forcing variable, age, crosses some cutoff points. Once individuals turn 2527 years old the types of allowed apprenticeship contracts are reduced by institutional constraints: workers can still be hired as apprentices but with a limited number of possible contracts. Once people turn 30 years old, they cannot be hired any longer as appren- 
tices. ${ }^{11}$ As the assignment is partly determined by the forcing variable, we are in "fuzzy" regression discontinuity (RD) design. In a fuzzy regression discontinuity design, the conditional probability of receiving the treatment $f\left(D_{i} \mid a g e_{i}\right) \equiv \operatorname{Pr}\left[D_{i} \mid a g e_{i}\right]$ is known to be discontinuous at some particular values of age $_{i} .{ }^{12}$

In order for the RD method to credibly identify the effect of contract type near the discontinuities, assumptions are needed. Hahn et al. (2001) formally studied the identification issues of the regression discontinuity method. They show that the key assumption of a valid regression discontinuity design is, apart from the known discontinuity of $\operatorname{Pr}\left[D_{i} \mid a g e_{i}\right]$ at some particular values of $a g e_{i}$, a local continuity restriction on $E\left[\mathbf{c}_{i} \mid a g e_{i}\right]$. This means that all the other factors determining the outcome variable must be evolving smoothly with respect to the forcing variable (Lee and Lemieux, 2010). If further variables jump at the threshold values, we would not be able to disentangle the effect of the variable of interest from the one of the other jumping variables. When the continuity assumption is satisfied, in the absence of treatment persons close to the cutoff point are similar (Hahn et al., 2001) and the average outcome of those right below the cutoff is a valid counterfactual for those right above the cutoff (Lee and Lemieux, 2010). If we are not willing to assume that the effect is homogeneous across individuals, identification is attained only for individuals who are close to the cutoff point of the forcing variable (Hahn et al., 2001; van der Klaauw, 2002).

A further assumption that we need is that individuals should not be able to precisely control the forcing variable. This might be the case for instance when the individual can anticipate what would happen if (s)he is below or above the threshold and can modify the realization of the forcing variable. This might be the case if individuals are able to precisely control the age at which they enter the labour market. Lee and Lemieux (2010) show that the inability to precisely control the assignment variable leads to a source of randomized variation in the treatment, which allows the identification of the treatment effect. In our framework, it is plausible to assume that individuals cannot precisely control the age at which entering the labour market. The probability of finding a job depends indeed also on the labour demand and on external factors that are not easily under the control of the unemployed. This is even more likely when the labour market tightness is low and in 2009 the crisis had already started to hit the Italian labour demand.

\footnotetext{
${ }^{11}$ Six individuals in our administrative dataset are reported to be hired as apprentices although older than 30 .

${ }^{12}$ The first cutoff point is in fact a function also of the region of residence: it is 25 years in the CentreNorth of Italy whilst it is 27 years in the South of Italy. We take it into account when estimating the model but, in order to keep the notation simple, we do not report it in the formal treatment of the method.
} 
Denote by $s_{1}$ an indicator variable equal to one if the individual is above the cutoff point of 25-27 years of age and $s_{2}$ an indicator variable equal to one if the individual is above the cutoff point of 30 years of age. The set of observed factors is collected into $\mathrm{x}$. The unobserved determinants of the probability of being treated and of the duration until a permanent contract are denoted by $\mathbf{v} \equiv\left(v_{a}, v_{p}\right)$. The joint conditional probability density function of entering the labour market with a contract $D=d$ and making a transition into a permanent contract $T=t$ days after the labour market entry is

$$
\begin{aligned}
\operatorname{Pr}\left(D=d, T=t \mid \mathbf{x}, \mathbf{v}, \text { age }, s_{1}, s_{2}\right) & =\operatorname{Pr}\left(D=d \mid \mathbf{x}, v_{a}, \text { age }, s_{1}, s_{2}\right) \\
& \times \operatorname{Pr}\left(T=t \mid \mathbf{x}, v_{p}, \text { age }, d\right) .
\end{aligned}
$$

This is the joint conditional probability if we observe a transition to a permanent contract before the end of the observed time window. If the individual has not entered a permanent job by that moment, this probability should be modified to take into account of exogenous right censoring. The joint conditional probability density function in case of exogenous right censoring after $T$ days is

$$
\begin{aligned}
\operatorname{Pr}\left(D=d, T>t \mid \mathbf{x}, \mathbf{v}, \text { age }, s_{1}, s_{2}\right) & =\operatorname{Pr}\left(D=d \mid \mathbf{x}, v_{a}, \text { age }, s_{1}, s_{2}\right) \\
& \times \operatorname{Pr}\left(T>t \mid \mathbf{x}, v_{p}, \text { age }, d\right) .
\end{aligned}
$$

The conditional marginal distribution of the first term on the right-hand side of Eq. (1) is the propensity score function and is specified as a logit model

$$
\operatorname{Pr}\left(D=1 \mid \mathbf{x}, v_{a}, a g e, s_{1}, s_{2}\right)=\frac{\exp \left[\mathbf{x} \boldsymbol{\beta}_{a}+\alpha_{1} s_{1}+\alpha_{2} s_{2}+f(a g e)+v_{a}\right]}{1+\exp \left[\mathbf{x} \boldsymbol{\beta}_{a}+\alpha_{1} s_{1}+\alpha_{2} s_{2}+f(a g e)+v_{a}\right]},
$$

where $f(a g e)$ is some continuous function of age that is continuous at the cutoff points. If the conditional marginal distribution of the second term on the right-hand side of Eq. (1) is absolutely continuous, it can be completely characterized by the hazard function. In its simplest formulation, we adopt the Mixed Proportional Hazard (MPH) specification

$$
\theta\left(t \mid \mathbf{x}, v_{p}, a g e, d\right)=\exp \left[\gamma(t)+\delta d+\mathbf{x} \boldsymbol{\beta}_{p}+k(a g e)+v_{p}\right]
$$

where $\exp [\gamma(t)]$ is the baseline hazard, common to all the individuals, and $k(a g e)$ is a control function continuous at the cutoff points. Misspecification of $f(a g e), k(a g e)$, or $\gamma(t)$ is a possible source of bias. In the empirical analysis we will therefore try different specifications of $f(a g e)$ and $k(a g e)$ and choose the ones minimizing the Akaike Informa- 
tion Criterion (AIC). The baseline hazard function $\gamma(t)$ is instead assumed to be piecewise constant.

In Eq. (4), the effect of the contract type on the hazard function to a permanent contract is given by $\delta$. It is a proportional effect and, as such, a strong assumption and a possible source of bias. In a more general specification we allow the treatment effect to be non proportional, i.e. to vary over time since the beginning of the spell:

$$
\theta\left(t \mid \mathbf{x}, v_{p}, a g e, d\right)=\exp \left[\gamma(t)+\delta(t) d+\mathbf{x} \boldsymbol{\beta}_{p}+k(a g e)+v_{p}\right]
$$

where $\delta(t)$ is the variation in the baseline hazard for the treated, i.e. for the apprenticeship.

The unobserved determinants $\mathbf{v} \equiv\left[v_{a}, v_{p}\right]$ are assumed to be independent on $(\mathbf{x}, a g e$, $\left.s_{1}, s_{2}\right)$. However, the two precesses, the one determining the propensity of apprenticeship and the one determining the time until a permanent job, will be correlated through the unobserved components. We take into account that the type of contract at labour market entry is endogenous in the hazard function to a permanent job by modelling the joint process. Instead of imposing distributional assumptions on the left-hand side of the joint density in Eq. (1), we impose parametric assumptions on the conditional densities on its right-hand side. In our fuzzy regression discontinuity approach, the discontinuities induced by the legislation setting are supposed to affect the probability of entering the labour market with an apprenticeship. However, they are excluded from the hazard function equation and they work as exclusion restrictions. We assume that once we control for age and for the type of contract, the hazard function does not depend on the discontinuity indicators $s_{1}$ and $s_{2}$. Misspecification fo the joint distribution might lead to biased estimates of the parameters of interest. In order to avoid too strict parametric assumptions, we will not restrict the correlation between $v_{a}$ and $v_{p}$. We rather follow Heckman and Singer (1984) and assume that $\mathbf{v} \equiv\left[v_{a}, v_{p}\right]$ is a random draw from a discrete distribution function with a finite and (a priori) unknown number $M$ of points of support. The probabilities associated to the points of support sum to one and, $\forall m=1, \ldots, M$, are denoted by

$$
p^{m}=\operatorname{Pr}\left(v_{a}=v_{a}^{m}, v_{p}=v_{p}^{m}\right) \equiv \operatorname{Pr}\left(\mathbf{v}=\mathbf{v}^{m}\right)
$$

and specified as logistic transforms:

$$
p^{m}=\frac{\exp \left(\lambda^{m}\right)}{\sum_{g=1}^{M} \exp \left(\lambda^{g}\right)} \quad \text { with } \quad m=1, \ldots, M \quad \text { and } \quad \lambda_{M}=0
$$




\subsection{The Likelihood Function}

The contribution to the likelihood function of an individual who flows into our sample with an apprenticeship contract $\left(d_{i}=1\right)$ and move to a permanent contract after $t_{i}$ days is given by

$$
\begin{array}{r}
L_{i}\left(d_{i}, t_{i} \mid \mathbf{x}_{i}, a g e_{i}, s_{i 1}, s_{i 2}, \mathbf{v}_{i} ; \Theta\right)=\frac{\exp \left[\mathbf{x}_{i} \boldsymbol{\beta}_{a}+\alpha_{1} s_{i 1}+\alpha_{2} s_{i 2}+f\left(a g e_{i}\right)+v_{i a}\right]}{1+\exp \left[\mathbf{x}_{i} \boldsymbol{\beta}_{a}+\alpha_{1} s_{i 1}+\alpha_{2} s_{i 2}+f\left(a g e_{i}\right)+v_{i a}\right]} \\
\times \theta\left(t_{i} \mid \mathbf{x}_{i}, a g e_{i}, d_{i}, v_{i p}\right) \exp \left[-\int_{\tau=0}^{t_{i}} \theta\left(t_{i} \mid \mathbf{x}_{i}, a g e_{i}, d_{i}, v_{i p}\right) d \tau\right],
\end{array}
$$

where $\Theta$ is the set of parameters characterizing the likelihood function. If the spell is right censored after $t_{i}$ days then

$$
\begin{aligned}
L_{i}\left(d_{i}, t_{i} \mid \mathbf{x}_{i}, a g e_{i}, s_{i 1}, s_{i 2}, \mathbf{v}_{i} ; \Theta\right) & =\frac{\exp \left[\mathbf{x}_{i} \boldsymbol{\beta}_{a}+\alpha_{1} s_{i 1}+\alpha_{2} s_{i 2}+f\left(a g e_{i}\right)+v_{i a}\right]}{1+\exp \left[\mathbf{x}_{i} \boldsymbol{\beta}_{a}+\alpha_{1} s_{i 1}+\alpha_{2} s_{i 2}+f\left(a g e_{i}\right)+v_{i a}\right]} \\
& \times \exp \left[-\int_{\tau=0}^{t_{i}} \theta\left(t_{i} \mid \mathbf{x}_{i}, a g e_{i}, d_{i}, v_{i p}\right) d \tau\right]
\end{aligned}
$$

It is not difficult to see how these individual contributions to the likelihood should be modified if an individual enter the labour market through a temporary job $\left(d_{i}=0\right)$ instead of as an apprentice $\left(d_{i}=1\right)$.

As $v_{i a}$ and $v_{i p}$ are unobserved, they must be integrated out of the likelihood function. Denote by $G(\cdot)$ the cumulative distribution function of $\mathbf{v}$. If $G(\cdot)$ is the above-mentioned discrete distribution, then the contribution to the likelihood function unconditional on unobserved heterogeneity for individual $i$ is

$$
L_{i}\left(d_{i}, t_{i} \mid \mathbf{x}_{i}, a g e_{i}, s_{i 1}, s_{i 2} ; \Theta\right)=\sum_{m=1}^{M} p^{m} L_{i}\left(d_{i}, t_{i} \mid \mathbf{x}_{i}, a g e_{i}, s_{i 1}, s_{i 2}, \mathbf{v}_{i}^{m} ; \Theta\right) \text {. }
$$

The log-likelihood function is the sum of the logarithm of this expression over all the individuals in our sample.

In the empirical analysis, we choose the number $M$ of points of support as suggested by Gaure et al.'s (2007) Monte Carlo simulations. We increase the number of points of support until there is no more an improvement in the log-likelihood function. Then, we select the model which minimizes the AIC. We always end up with choosing the model with $M=3$ points of support, independently of the model specification. 


\section{Estimation Results}

In Subsection 5.1 we report the estimation results of the benchmark models in which the functions $k(a g e)$ and $f(a g e)$ are polynomials of order three. We tried also with polynomials of lower and higher orders but the degree of order three is the one which minimizes the AIC. We also specified the age functions as spline continuous functions with knots at $21,24,27$, and 31 years of age. Also in this case, we were not able to do better in terms of the AIC and the estimation results were very close to those of the benchmark model. ${ }^{13}$

Subsection 5.2 reports some simulations results which are aimed at evaluating the goodness-of-fit of the models and quantify the impact of the contract type on the probability of finding a permanent job in terms of average treatment effect on the treated (ATT).

Finally, in Subsection 5.3, we briefly discuss the robustness checks that we performed.

\subsection{Estimation Results of the Benchmark Model}

Table 3 reports the estimation result of the logit model for the probability of entering the labour market with an apprenticeship (rather than a temporary job). In specification (1) we do not consider the presence of unobserved heterogeneity, whilst in specification (2) we take into account that the processes determining the initial contract and the probability of moving to a permanent contract might be correlated through unobserved determinants. The estimation results of the hazard function are reported instead in Table 4. In both specifications, the apprenticeship indicator is assumed to proportionally affect the hazard rate to a permanent contract.

The discontinuity at age 30 has, as expected, a negative impact on the probability of apprenticeship. The discontinuity at 25-27 years is instead not significant. This finding has an implication in terms of interpretation of the causal effect of apprenticeship on the hazard rate to a permanent contract. As a significant discontinuity is detected only at 30 years of age, the eventual effect of apprenticeship on the hazard rate can be interpreted only as a local effect around the cutoff, unless we impose an arbitrary assumption of homogeneous treatment effect across age. Age negatively affects the probability of apprenticeship. Women and people from the South of Italy and Lazio are less likely to be apprentices. Individuals with lower secondary or higher secondary education have the higher probability to become apprentices. Immigrants from outside the UE are more

\footnotetext{
${ }^{13}$ These estimation results of the models with alternative specification of the age functions are not reported for the sake of brevity but are available from the authors upon request.
} 
Table 3: Estimation results of the logit model for entering the labour market with an apprenticeship

\begin{tabular}{|c|c|c|c|c|c|c|}
\hline & \multicolumn{3}{|c|}{$\begin{array}{c}\text { Without unobserved } \\
\text { heterogeneity } \\
(1)\end{array}$} & \multicolumn{3}{|c|}{$\begin{array}{c}\text { With unobserved } \\
\text { heterogeneity } \\
(2)\end{array}$} \\
\hline & Coeff. & & Std. Err. & Coeff. & & Std. Err. \\
\hline Discontinuity at age $25-27$ & -0.074 & & 0.118 & -0.009 & & 0.182 \\
\hline Discontinuity at age 30 & -2.750 & $* * *$ & 0.488 & -3.797 & $* * *$ & 0.926 \\
\hline Age (years)/10 & -2.216 & $* * *$ & 0.730 & -2.881 & $* *$ & 1.189 \\
\hline Age squared/100 & 1.887 & & 1.521 & 1.743 & & 2.382 \\
\hline Age cubic/10000 & -13.444 & & 8.461 & -15.972 & & 13.546 \\
\hline Female & -0.200 & $* * *$ & 0.050 & -0.292 & $* * *$ & 0.085 \\
\hline Regional unemployment rate & 1.337 & $* * *$ & 0.355 & 1.847 & $* * *$ & 0.571 \\
\hline \multicolumn{7}{|c|}{ Education-Reference: None or primary } \\
\hline Lower secondary & 0.478 & $* * *$ & 0.079 & 0.762 & $* * *$ & 0.151 \\
\hline Higher secondary & 0.444 & $* * *$ & 0.082 & 0.706 & $* * *$ & 0.151 \\
\hline University or more & -0.186 & & 0.131 & -0.477 & $* *$ & 0.234 \\
\hline \multicolumn{7}{|c|}{ Region-Reference: Piemonte-Valle d'Aosta } \\
\hline Lombardia & -0.282 & $* * *$ & 0.109 & -0.484 & $* * *$ & 0.178 \\
\hline Trentino Alto Adige & -0.573 & $* * *$ & 0.172 & -1.033 & $* * *$ & 0.292 \\
\hline Veneto & 0.605 & $* * *$ & 0.168 & 0.848 & $* * *$ & 0.274 \\
\hline Friuli Venezia Giulia & 0.157 & & 0.184 & 0.240 & & 0.289 \\
\hline Liguria & 0.618 & $* * *$ & 0.147 & 0.952 & $* * *$ & 0.249 \\
\hline Emilia Romagna & -0.083 & & 0.132 & -0.146 & & 0.206 \\
\hline Toscana & 0.242 & $* *$ & 0.118 & 0.378 & $* *$ & 0.187 \\
\hline Umbria & 0.186 & & 0.176 & 0.292 & & 0.277 \\
\hline Marche & 0.083 & & 0.149 & 0.190 & & 0.234 \\
\hline Lazio & -0.707 & $* * *$ & 0.132 & -1.016 & $* * *$ & 0.232 \\
\hline Abruzzo-Molise & -0.593 & $* * *$ & 0.168 & -0.801 & $* * *$ & 0.272 \\
\hline Campania & -2.018 & $* * *$ & 0.272 & -3.073 & $* * *$ & 0.530 \\
\hline Puglia & -1.539 & $* * *$ & 0.251 & -2.327 & $* * *$ & 0.457 \\
\hline Basilicata-Calabria & -1.921 & $* * *$ & 0.247 & -3.033 & $* * *$ & 0.518 \\
\hline Sicilia-Sardegna & -1.924 & $* * *$ & 0.284 & -2.860 & $* * *$ & 0.531 \\
\hline \multicolumn{7}{|c|}{ Nationality - Reference: Italian } \\
\hline EU & -0.314 & $* * *$ & 0.098 & -0.512 & $* * *$ & 0.164 \\
\hline Non EU & 0.266 & $* * *$ & 0.082 & 0.351 & $* * *$ & 0.132 \\
\hline \multicolumn{7}{|c|}{ Points of support of unobserved heterogeneity } \\
\hline$v_{1}$ & -1.432 & $* * *$ & 0.217 & -3.090 & $* * *$ & 0.532 \\
\hline$v_{2}$ & - & & - & 4.475 & $* * *$ & 1.101 \\
\hline$v_{3}$ & - & & - & -0.190 & & 0.394 \\
\hline
\end{tabular}

Notes: *** Significant at $1 \%$; ** significant at 5\%; * significant at $10 \%$. 
Table 4: Estimation results of the hazard function into a permanent job - proportional effect of apprenticeship

\begin{tabular}{|c|c|c|c|c|c|c|}
\hline & \multicolumn{3}{|c|}{$\begin{array}{c}\text { Without unobserved } \\
\text { heterogeneity } \\
(1)\end{array}$} & \multicolumn{3}{|c|}{$\begin{array}{c}\text { With unobserved } \\
\text { heterogeneity } \\
(2)\end{array}$} \\
\hline & Coeff. & & Std. Err. & Coeff. & & Std. Err. \\
\hline Apprenticeship & -0.028 & & 0.046 & -1.829 & $* * *$ & 0.219 \\
\hline Age (years)/10 & 1.337 & $* * *$ & 0.290 & 1.084 & $* * *$ & 0.401 \\
\hline Age squared/100 & -1.013 & $* * *$ & 0.378 & -1.224 & $* *$ & 0.523 \\
\hline Age cubic/10000 & 2.670 & $*$ & 1.421 & 3.698 & $*$ & 1.989 \\
\hline Female & -0.168 & $* * *$ & 0.025 & -0.261 & $* * *$ & 0.037 \\
\hline Regional unemployment rate & 0.121 & & 0.113 & 0.074 & & 0.115 \\
\hline \multicolumn{7}{|c|}{ Education-Reference: None or primary } \\
\hline Lower secondary & 0.081 & $* *$ & 0.038 & 0.197 & $* * *$ & 0.056 \\
\hline Higher secondary & 0.004 & & 0.040 & 0.082 & & 0.058 \\
\hline University or more & -0.130 & $* *$ & 0.052 & -0.233 & $* * *$ & 0.073 \\
\hline \multicolumn{7}{|c|}{ Region-Reference: Piemonte-Valle d'Aosta } \\
\hline Lombardia & 0.184 & $* * *$ & 0.055 & 0.103 & & 0.083 \\
\hline Trentino Alto Adige & -0.293 & $* * *$ & 0.087 & -0.580 & $* * *$ & 0.119 \\
\hline Veneto & 0.107 & & 0.075 & 0.112 & & 0.101 \\
\hline Friuli Venezia Giulia & 0.126 & & 0.093 & 0.161 & & 0.135 \\
\hline Liguria & 0.044 & & 0.088 & 0.121 & & 0.132 \\
\hline Emilia Romagna & -0.150 & $* *$ & 0.065 & -0.309 & $* * *$ & 0.092 \\
\hline Toscana & -0.147 & $* *$ & 0.068 & -0.200 & $* *$ & 0.097 \\
\hline Umbria & -0.010 & & 0.102 & 0.044 & & 0.147 \\
\hline Marche & -0.178 & $* *$ & 0.090 & -0.285 & $* *$ & 0.129 \\
\hline Lazio & -0.254 & $* * *$ & 0.064 & -0.422 & $* * *$ & 0.091 \\
\hline Abruzzo-Molise & -0.003 & & 0.084 & -0.070 & & 0.123 \\
\hline Campania & -0.285 & $* * *$ & 0.107 & -0.577 & $* * *$ & 0.133 \\
\hline Puglia & -0.479 & $* * *$ & 0.097 & -0.752 & $* * *$ & 0.123 \\
\hline Basilicata-Calabria & -0.621 & $* * *$ & 0.102 & -1.009 & $* * *$ & 0.132 \\
\hline Sicilia-Sardegna & -0.449 & $* * *$ & 0.102 & -0.704 & $* * *$ & 0.125 \\
\hline \multicolumn{7}{|c|}{ Nationality - Reference: Italian } \\
\hline EU & -0.357 & $* * *$ & 0.051 & -0.477 & $* * *$ & 0.068 \\
\hline Non EU & 0.278 & $* * *$ & 0.040 & 0.476 & $* * *$ & 0.063 \\
\hline \multicolumn{7}{|c|}{ Baseline hazard-Reference: $(0,3]$ months } \\
\hline$(3,6]$ months & 0.406 & $* * *$ & 0.061 & 0.463 & $* * *$ & 0.062 \\
\hline$(6,9]$ months & 0.397 & $* * *$ & 0.062 & 0.528 & $* * *$ & 0.064 \\
\hline$(9,12]$ months & 0.698 & $* * *$ & 0.059 & 0.895 & $* * *$ & 0.067 \\
\hline$(12,15]$ months & 0.486 & $* * *$ & 0.062 & 0.790 & $* * *$ & 0.073 \\
\hline$(15,18]$ months & 0.355 & $* * *$ & 0.064 & 0.723 & $* * *$ & 0.080 \\
\hline$(18,21]$ months & 0.326 & $* * *$ & 0.065 & 0.765 & $* * *$ & 0.085 \\
\hline$(21,24]$ months & 0.344 & $* * *$ & 0.065 & 0.845 & $* * *$ & 0.092 \\
\hline$(24,27]$ months & 0.399 & $* * *$ & 0.065 & 0.985 & $* * *$ & 0.095 \\
\hline$(27,30]$ months & 0.104 & & 0.071 & 0.745 & $* * *$ & 0.105 \\
\hline$(30,33]$ months & 0.055 & & 0.076 & 0.751 & $* * *$ & 0.113 \\
\hline$(33,36]$ months & 0.034 & & 0.085 & 0.779 & $* * *$ & 0.123 \\
\hline more than 36 months & 0.359 & $* * *$ & 0.082 & 1.200 & $* * *$ & 0.123 \\
\hline \multicolumn{7}{|c|}{ Points of support of unobserved heterogeneity } \\
\hline$v_{1}$ & -8.761 & $* * *$ & 0.109 & -9.822 & $* * *$ & 0.208 \\
\hline$v_{2}$ & - & & - & -6.302 & $* * *$ & 0.361 \\
\hline$v_{3}$ & - & & - & -7.246 & $* * *$ & 0.175 \\
\hline \multicolumn{7}{|c|}{ Probability masses $-\lambda_{3}$ normalized to 0} \\
\hline$\lambda_{1}$ & - & & - & 0.762 & $* * *$ & 0.141 \\
\hline$\lambda_{2}$ & - & & - & -2.248 & $* * *$ & 0.410 \\
\hline Observations & \multicolumn{3}{|c|}{22,207} & \multicolumn{3}{|c|}{22,207} \\
\hline Log-likelihood & \multicolumn{3}{|c|}{$-65,077.7$} & \multicolumn{3}{|c|}{$-65,026.7$} \\
\hline \# of parameters & \multicolumn{3}{|c|}{67} & \multicolumn{3}{|c|}{73} \\
\hline $\mathrm{AIC} / N$ & \multicolumn{3}{|c|}{5.867} & \multicolumn{3}{|c|}{5.863} \\
\hline
\end{tabular}

Notes: *** Significant at $1 \%$; ** significant at $5 \%$; * significant at $10 \%$. 
likely than Italians to enter the labour market through an apprenticeship, whilst those from inside the UE are less likely.

The proportional effect of apprenticeship on the hazard rate to a permanent job changes when we control for the presence of unobserved heterogeneity. From not significant and close to zero, it becomes highly significant and with an important negative effect on the conditional instantaneous probability of moving to a permanent contract: entering the labour market as an apprentice rather than with a temporary contract lowers the hazard rate to a permanent contract by almost $84 \% .^{14}$

In specification (2), the estimated baseline hazard to a permanent contract displays a non-monotonic profile, although roughly increasing. It increases during the first year, then it stabilizes until the end of the third year when it increases again after the end of the third year after labour market entry. This profile is very different from the one in specification (1). When unobserved heterogeneity is neglected, the baseline hazard is downward biased: it increases up to the end of the first year since labour market entry, then it goes back to the initial value and only at the end of the third year it increases again. This is the result of a form of selectivity bias induced by the fact that more able and more motivated individuals find a permanent job sooner and the surviving sample is therefore characterized by a decreasing average level of the unobserved determinants. ${ }^{15}$

The negative effect of apprenticeship on the hazard rate to a permanent job might be induced by misspecification. As the institutional setting requires the employers to provide the apprentices with training, the apprentices might have to wait until the end of the training before being promoted to a permanent job within that firm. Moreover, if part of the skills they learn during the training is general, they might prefer to wait the end of the training period and get the training certification before looking for a permanent job in another firm. Moreover, once the apprentices have finished the training course and got the certification, they might be more likely than temporary workers to find a permanent contract as they can signal their competences and skills. This would imply that the restriction on the effect of apprenticeship to be proportional might be too strong and lead to biased results.

In Table 5 we report the estimation results of the hazard function once we allow the

\footnotetext{
${ }^{14}$ As the estimated coefficient of the apprenticeship indicator is -1.829 and given the model specification in Eq. (4), the impact on the hazard rate to a permanent contract is given by $[\exp (-1.829)-1] \times 100=$ $-83.94 \%$.

${ }^{15}$ See Lancaster (1992) or Salant (1977) for an early discussion on the issue of neglected heterogeneity and sorting in duration models.
} 
apprenticeship effect to be non proportional. ${ }^{16}$ We allow the effect of apprenticeship to affect the baseline rate differently at each year of elapsed duration since the labour market entry. ${ }^{17}$ We find that the apprentices are less likely to move to a permanent contract in the first year since the labour market entry. The effect is however not significantly different from zero. In the second year, the apprentices become more likely to find a permanent job than temporary workers, although the effect is still not significant. From the beginning of the third year onward, the apprentices are found to be significantly more likely than temporary workers to find a permanent job.

There might be two explanations for our findings. First, as firms are legally obliged to provide their apprentices with training, the apprentices might accumulate more human capital than temporary workers and, thereby, they might be more likely to get a permanent job once the apprenticeship period expires. Second, the apprenticeship system might be more effective in screening job candidates than other forms of temporary workers. As suggested by Autor (2001), training can facilitate screening: training tests workers' skills and releases thereby private information about workers' ability and motivations. ${ }^{18}$ Once the apprenticeship has expired, the employer can decide whether to get locked into an open-ended job relationship with high firing costs on the basis of a richer and more complete information than that of temporary workers.

If the screening explanation holds and the information releases by training during the apprenticeship is private, then it cannot be used by outside firms. Hence, if in our econometric model we distinguish between transitions to a permanent job within the same firm providing the apprenticeship and transitions to a permanent job in a different firm, we should find that apprentices are more likely to get a permanent job within the same firm than in other firms. By distinguishing between transitions to a permanent job within the same firm and transitions to a permanent job in a different firm and by contrasting the transition intensities of apprentices with the ones of temporary workers, we can also shed some light on the nature of human capital that apprentices and temporary workers accumulate over time. Table 6 reports estimation results of a competing risks MPH model in which we distinguish between the entry into a permanent job in the same firm and the entry into a permanent job in a different firm. Figure 4 plots the estimated baseline hazard

\footnotetext{
${ }^{16}$ For the sake of brevity we do not report the estimation results of the logit model. We obtain estimation results very close to those reported in Table 3. They are available from the authors upon request.

${ }^{17} \mathrm{We}$ also allowed the profile of the baseline hazard of apprentices to be completely different from the baseline hazard of temporary workers. However, model specifications (3) and (4) were preferred to more flexible ones according to the AIC.

${ }^{18}$ For this explanation to be important we need to assume that apprentices are more likely than temporary workers to receive firm provided training.
} 
Table 5: Estimation results of hazard function into permanent job - non proportional effect of apprenticeship

\begin{tabular}{|c|c|c|c|c|c|c|}
\hline & \multicolumn{3}{|c|}{$\begin{array}{c}\text { Without unobserved } \\
\text { heterogeneity } \\
\text { (3) }\end{array}$} & \multicolumn{3}{|c|}{$\begin{array}{l}\text { With unobserved } \\
\text { heterogeneity } \\
\text { (4) }\end{array}$} \\
\hline & Coeff. & & Std. Err. & Coeff. & & Std. Err. \\
\hline Age (years)/10 & 1.279 & $* * *$ & 0.289 & 1.653 & $* * *$ & 0.334 \\
\hline Age squared/100 & -0.941 & $* * *$ & 0.377 & -1.161 & $* * *$ & 0.441 \\
\hline Age cubic/10000 & 2.414 & $*$ & 1.421 & 2.936 & $*$ & 1.677 \\
\hline Female & -0.170 & $* * *$ & 0.025 & -0.186 & $* * *$ & 0.031 \\
\hline Regional unemployment rate & 0.162 & & 0.113 & 0.198 & $*$ & 0.116 \\
\hline \multicolumn{7}{|c|}{ Education-Reference: None or primary } \\
\hline Lower secondary & 0.081 & $* *$ & 0.038 & 0.082 & $*$ & 0.047 \\
\hline Higher secondary & 0.004 & & 0.040 & -0.013 & & 0.048 \\
\hline University or more & -0.129 & $* * *$ & 0.052 & -0.188 & $* * *$ & 0.061 \\
\hline \multicolumn{7}{|c|}{ Nationality - Reference: Italian } \\
\hline EU & -0.354 & $* * *$ & 0.051 & -0.354 & $* * *$ & 0.059 \\
\hline Non EU & 0.280 & $* * *$ & 0.040 & 0.342 & $* * *$ & 0.051 \\
\hline \multicolumn{7}{|c|}{ Baseline hazard for temporary workers-Reference: $(0,3]$ months } \\
\hline$(3,6]$ months & 0.406 & $* * *$ & 0.061 & 0.426 & $* * *$ & 0.062 \\
\hline$(6,9]$ months & 0.396 & $* * *$ & 0.062 & 0.444 & $* * *$ & 0.064 \\
\hline$(9,12]$ months & 0.697 & $* * *$ & 0.059 & 0.772 & $* * *$ & 0.065 \\
\hline$(12,15]$ months & 0.466 & $* * *$ & 0.062 & 0.576 & $* * *$ & 0.073 \\
\hline$(15,18]$ months & 0.335 & $* * *$ & 0.064 & 0.477 & $* * *$ & 0.079 \\
\hline$(18,21]$ months & 0.307 & $* * *$ & 0.066 & 0.483 & $* * *$ & 0.083 \\
\hline$(21,24]$ months & 0.324 & $* * *$ & 0.066 & 0.533 & $* * *$ & 0.089 \\
\hline$(24,27]$ months & 0.322 & $* * *$ & 0.066 & 0.535 & $* * *$ & 0.094 \\
\hline$(27,30]$ months & 0.025 & & 0.071 & 0.281 & $* * *$ & 0.102 \\
\hline$(30,33]$ months & -0.028 & & 0.076 & 0.271 & $* *$ & 0.109 \\
\hline$(33,36]$ months & -0.053 & & 0.086 & 0.292 & $* *$ & 0.120 \\
\hline more than 36 months & -0.017 & & 0.093 & 0.327 & $* *$ & 0.132 \\
\hline \multicolumn{7}{|c|}{ Variation in the baseline hazard for apprentices } \\
\hline$(0,12]$ months & -0.515 & $* * *$ & 0.084 & -0.118 & & 0.514 \\
\hline$(12,24]$ months & -0.223 & $* * *$ & 0.079 & 0.337 & & 0.535 \\
\hline$(24,36]$ months & 0.310 & $* * *$ & 0.078 & 1.352 & $* *$ & 0.542 \\
\hline more than 36 months & 1.600 & $* * *$ & 0.121 & 6.186 & $* * *$ & 0.557 \\
\hline \multicolumn{7}{|c|}{ Points of support of unobserved heterogeneity } \\
\hline$v_{1}$ & -8.735 & $* * *$ & 0.109 & -14.875 & $* * *$ & 0.541 \\
\hline$v_{2}$ & - & & - & -8.050 & $* * *$ & 0.550 \\
\hline$v_{3}$ & - & & - & -8.644 & $* * *$ & 0.211 \\
\hline \multicolumn{7}{|c|}{ Probability masses $-\lambda_{3}$ normalized to 0} \\
\hline$\lambda_{1}$ & - & & - & -0.271 & & 0.253 \\
\hline$\lambda_{2}$ & - & & - & -1.342 & $* * *$ & 0.485 \\
\hline Observations & \multicolumn{3}{|c|}{22,207} & \multicolumn{3}{|c|}{22,207} \\
\hline Log-likelihood & \multicolumn{3}{|c|}{$-64,976.0$} & \multicolumn{3}{|c|}{$-64,885.5$} \\
\hline \# of parameters & \multicolumn{3}{|c|}{70} & \multicolumn{3}{|c|}{76} \\
\hline $\operatorname{AIC} / N$ & \multicolumn{3}{|c|}{5.858} & \multicolumn{3}{|c|}{5.851} \\
\hline
\end{tabular}

Notes: *** Significant at $1 \%$;** significant at $5 \%$; significant at $10 \%$.

Regional dummies are included in the model but the corresponding estimation results are not reported for the sake of brevity. 
by contract type in a single risk framework (estimation results presented in Table 5) and in a competing risks setting (estimation results presented in Table 6). Two findings are worthy of mention. Firstly, apprentices are more likely to move to permanent job within the same firm than to a different firm. The specificity of the human capital accumulation and the private nature of the information on workers' ability released by training might explain this finding. Secondly, the transition intensity to a permanent job in the same firm is always significantly higher for apprentices. The transition intensity to a permanent job in a different firm is instead always higher for temporary workers. Apprentices accumulating more firm specific human capital and temporary workers accumulating more general skills might explain this second evidence.

Finally, we briefly comment on the estimated coefficients of the other explanatory variables reported. Women and individuals with a university degree are less likely to be hired as apprentices (Table 3). Women show lower hazard rates to permanent jobs than men, towards both the entry firm and other firms. Even if individuals with a university degree have on average lower hazard rates, they exhibit a higher hazard towards the entry firm, probably because training for the high educated is more costly and the specificity of human capital is higher (model (4) of Table 5 and Table 6). The regional unemployment rate at the time of entry in the labour market is strongly significant in the selection model (2) of Table 3: this means that the higher the unemployment rate, the higher the probability that individuals are hired with an apprenticeship contract. This contrasts with the evidence in Askilden and Nilsen (2005) who find that apprentices are employed when unemployment is low. They suggest that when the tightness of the labour market is higher, it is difficult to recruit skilled workers and therefore firms might prefer to recruit unskilled workers as apprentices. Our finding might be explained by the fact that we do not have a regressor for the business cycle. Hence, the unemployment rate might proxy the state of the economy. In downturns firms might prefer to use temporary jobs as a buffer. Hence, firms might stop hiring temporary workers and terminate the job relationship with the temporary workers at the end of the contract, explaining why we find that individuals are more less likely to be hired with a temporary job than with an apprenticeship contract when the unemployment rate is higher. Non-European citizens are more appealing to firms as apprentices than Italian: they show a higher probability of entering the labour market as apprentices and a higher hazard rate towards permanent jobs. The probability of getting an apprenticeship is decreasing with age but older individuals are more likely to find a permanent job. The hazard towards permanent employment in the same firm is higher for younger workers, whereas the one towards a different firm is higher for older 
employees.

Figure 4: Estimated baseline transition intensities to permanent work

Transition intensity to a permanent work

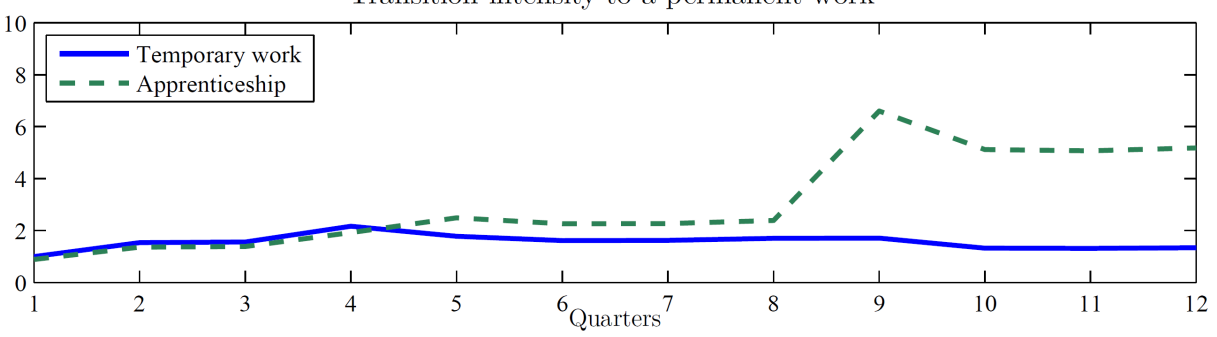

Transition intensity to a permanent work in the same firm

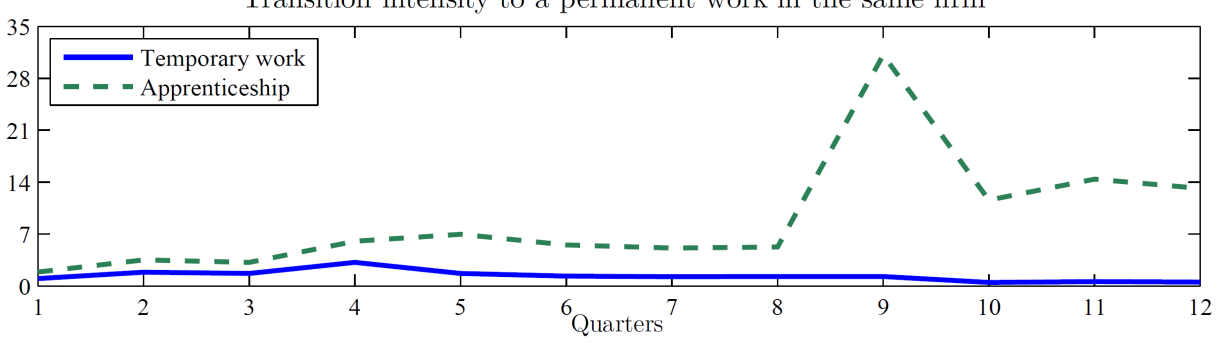

Transition intensity to a permanent work in a different firm

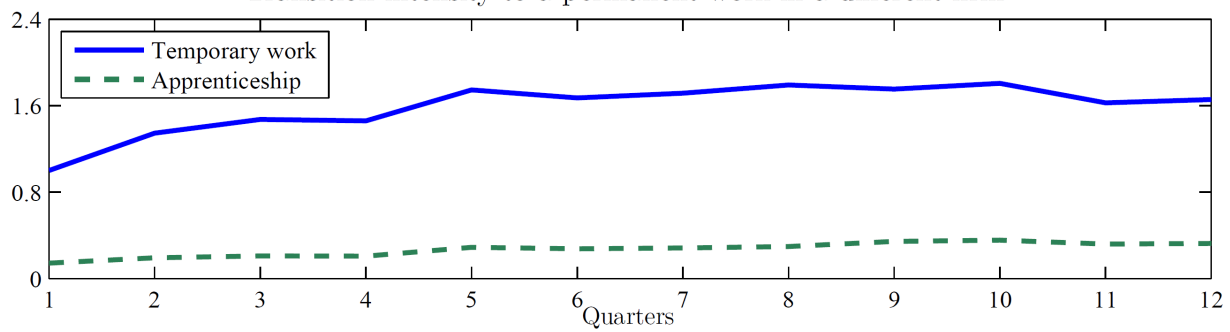

\subsection{Simulations}

In this subsection we exploit the estimated parameters of the benchmark model to simulate apprentices' probabilities of finding a permanent job in different moments of time and contrast them with the counterfactual probabilities if they were hired on the basis of another type of temporary job. By doing so, we estimate ATTs. Since the effect is locally identified, we will replicate the same evaluation focusing only on apprentices close to the cutoff point of 30 years of age at sample entry.

Given the mixture of parametric and non-parametric functional forms and since the reliability of the microsimulations depends on the capability of our model to predict the contract type and the duration until a permanent job, we first check the goodness-of-fit 
Table 6: Estimation results of hazard function into permanent job - competing risks and non proportional effect of apprenticeship

\begin{tabular}{|c|c|c|c|c|c|c|}
\hline & \multicolumn{3}{|c|}{$\begin{array}{l}\text { Transition to permanent job } \\
\text { in the same firm }\end{array}$} & \multicolumn{3}{|c|}{$\begin{array}{c}\text { Transition to permanent job } \\
\text { in a different firm }\end{array}$} \\
\hline & Coeff. & & Std. Err. & Coeff. & & Std. Err. \\
\hline Age (years)/10 & 1.737 & $* * *$ & 0.522 & 0.832 & $*$ & 0.454 \\
\hline Age squared/100 & -0.847 & & 0.666 & -1.195 & $* *$ & 0.598 \\
\hline Age cubic/10000 & 1.476 & & 2.478 & 3.787 & $*$ & 2.268 \\
\hline Female & -0.232 & $* * *$ & 0.043 & -0.154 & $* * *$ & 0.042 \\
\hline Regional unemployment rate & 0.284 & & 0.210 & 0.145 & & 0.141 \\
\hline \multicolumn{7}{|c|}{ Education - Reference: None or primary } \\
\hline Lower secondary & 0.125 & $*$ & 0.069 & 0.160 & $* * *$ & 0.062 \\
\hline Higher secondary & 0.257 & $* * *$ & 0.071 & -0.134 & $* *$ & 0.065 \\
\hline University or more & 0.160 & $*$ & 0.086 & -0.421 & $* * *$ & 0.085 \\
\hline \multicolumn{7}{|l|}{ Nationality - Reference: Italian } \\
\hline EU & -0.464 & $* * *$ & 0.090 & -0.342 & $* * *$ & 0.076 \\
\hline Non EU & -0.040 & & 0.075 & 0.631 & $* * *$ & 0.073 \\
\hline \multicolumn{7}{|c|}{ Baseline hazard for temporary workers-Reference: $(0,3]$ months } \\
\hline$(3,6]$ months & 0.624 & $* * *$ & 0.098 & 0.296 & $* * *$ & 0.082 \\
\hline$(6,9]$ months & 0.524 & $* * *$ & 0.101 & 0.387 & $* * *$ & 0.086 \\
\hline$(9,12]$ months & 1.160 & $* * *$ & 0.094 & 0.377 & $* * *$ & 0.092 \\
\hline$(12,15]$ months & 0.532 & $* * *$ & 0.104 & 0.557 & $* * *$ & 0.094 \\
\hline$(15,18]$ months & 0.302 & $* * *$ & 0.109 & 0.514 & $* * *$ & 0.099 \\
\hline$(18,21]$ months & 0.222 & $* *$ & 0.111 & 0.539 & $* * *$ & 0.105 \\
\hline$(21,24]$ months & 0.251 & $* *$ & 0.112 & 0.582 & $* * *$ & 0.108 \\
\hline$(24,27]$ months & 0.252 & $* *$ & 0.112 & 0.562 & $* * *$ & 0.112 \\
\hline$(27,30]$ months & -0.736 & $* * *$ & 0.142 & 0.591 & $* * *$ & 0.116 \\
\hline$(30,33]$ months & -0.519 & $* * *$ & 0.140 & 0.486 & $* * *$ & 0.126 \\
\hline$(33,36]$ months & -0.608 & $* * *$ & 0.165 & 0.504 & $* * *$ & 0.138 \\
\hline more than 36 months & -0.368 & $* *$ & 0.167 & 0.495 & $* * *$ & 0.152 \\
\hline \multicolumn{7}{|c|}{ Variation in the baseline hazard for apprentices } \\
\hline$(0,12]$ months & 0.637 & $* * *$ & 0.220 & -1.946 & $* * *$ & 0.253 \\
\hline$(12,24]$ months & 1.411 & $* * *$ & 0.198 & -1.800 & $* * *$ & 0.242 \\
\hline$(24,36]$ months & 3.187 & $* * *$ & 0.182 & -1.627 & $* * *$ & 0.227 \\
\hline more than 36 months & 8.469 & $* * *$ & 0.317 & -0.868 & $* * *$ & 0.279 \\
\hline \multicolumn{7}{|c|}{ Points of support of unobserved heterogeneity } \\
\hline$v_{1}$ & -9.767 & $* * *$ & 0.203 & -10.657 & $* * *$ & 0.515 \\
\hline$v_{2}$ & -17.760 & $* * *$ & 0.473 & -7.845 & $* * *$ & 0.207 \\
\hline$v_{3}$ & -10.015 & $* * *$ & 0.407 & -5.582 & $* * *$ & 0.373 \\
\hline \multicolumn{7}{|c|}{ Probability masses $-\lambda_{3}$ normalized to 0} \\
\hline$\lambda_{1}$ & 3.712 & $* * *$ & 0.224 & & & \\
\hline$\lambda_{2}$ & 3.247 & $* * *$ & 0.257 & & & \\
\hline Observations & \multicolumn{6}{|c|}{22,207} \\
\hline Log-likelihood & \multicolumn{6}{|c|}{$-68,962.1$} \\
\hline \# of parameters & \multicolumn{6}{|c|}{120} \\
\hline $\mathrm{AIC} / N$ & \multicolumn{6}{|c|}{6.222} \\
\hline
\end{tabular}

Notes: *** Significant at $1 \%$; ** significant at $5 \%$; $*$ significant at $10 \%$.

Regional dummies are included in the model but the corresponding estimation results are not reported for the sake of brevity. 
of the estimated benchmark model. The goodness-of-fit statistics are constructed on the basis of simulations of 999 sequences of contract choices and durations until a permanent job for each individual in the sample. Since we replicate the simulations 999 times, we can construct $95 \%$ confidence intervals of the predicted frequencies and check whether they are close enough to the empirical ones. The simulation algorithm with regard the goodness-of-fit is in Appendix A.

Table 7 reports the goodness-of-fit statistics. The actual frequencies lying in the $95 \%$ confidence interval of the predicted ones are in bold. The model tends to slightly overpredict the fraction of apprentices, although the misalignment size is not large. The model performs quite well in predicting the fraction of right-censored spells, i.e. of those individuals who are not able to move to a permanent job before the end of their time window. The fraction of right-censored spells is slightly overpredicted for apprentices and underpredicted for temporary workers. Finally, the model performs reasonably well in predicting the absolute frequencies of quarterly exits towards a permanent job, both for temporary workers and apprentices. The fit is extremely good especially for short and medium durations. The misaligment becomes instead more important for long durations.

In order to quantify the effect of entering the labour market with an apprenticeship rather than a temporary contract, for each apprentice we predict, by way of microsimulations, the month of exit towards a permanent job under two scenarios: firstly, by keeping fixed the contract type at the actual value and, secondly, by pretending that the apprentices entered the labour market through a temporary contract. ${ }^{19}$ By averaging across the population of apprentices, we compute the probabilities of having already entered a permanent job under the actual and the counterfactual contract. Finally, by contrasting these two probabilities, we obtain an estimate of the ATT, i.e. the variation in the probability of finding a permanent job generated by having an apprenticeship rather than a temporary contract for the apprentices. Column (a) of Table 8 reports the estimated probability of having already entered a permanent job within $t$ months from the start of the apprenticeship. Column (b) displays instead the estimated counterfactual probabilities if the apprentices entered the sample with a temporary arrangement rather than the apprenticeship. Column (a-b) is the difference between column (a) and column (b), i.e. the estimated ATT. The simulation is run both on the whole sample of apprentices (top panel of Table 8) and on the subset of apprentices that are 29 years old at the moment of sample entry (bottom panel of Table 8). Since the effect is locally identified in the proximity of the

\footnotetext{
${ }^{19}$ The simulation algorithm used here is the same as the one used for computing the goodness-of-fit statistics.
} 


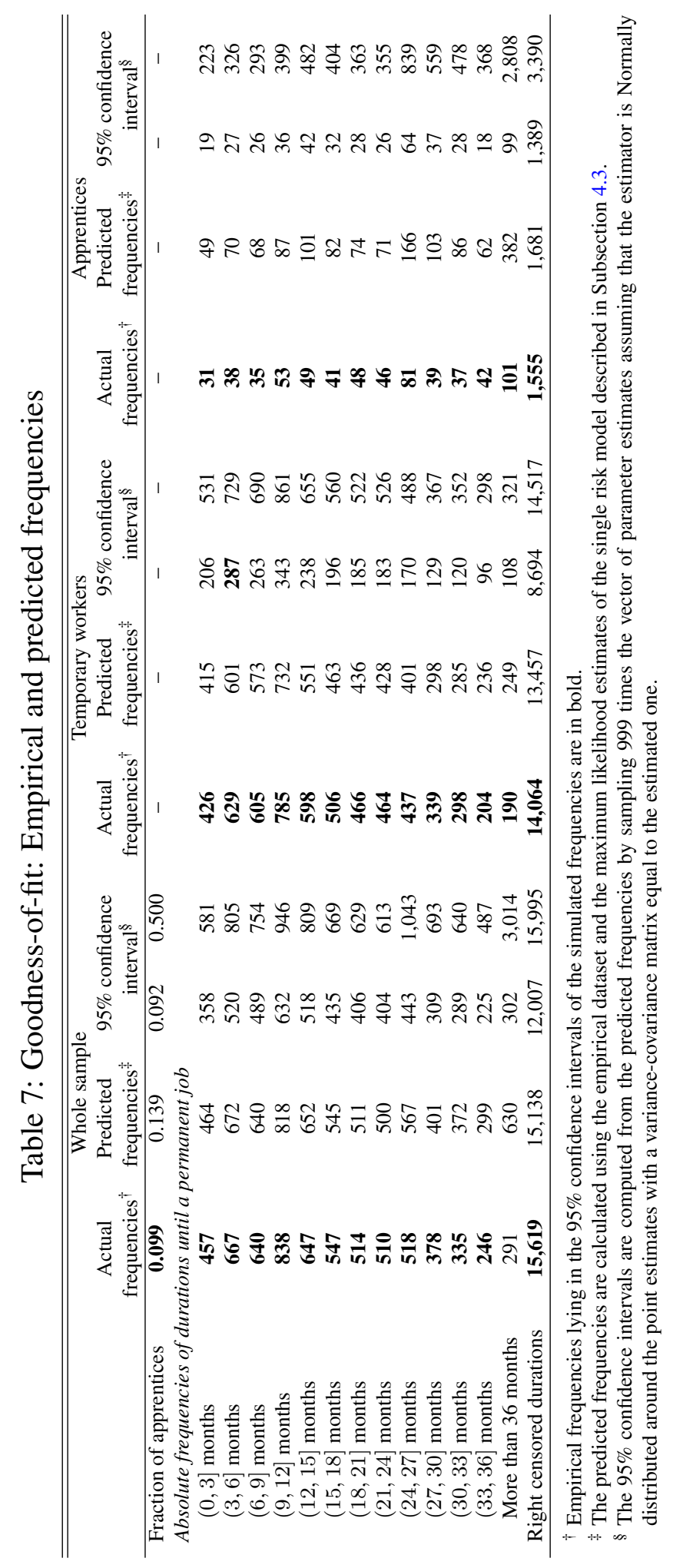


cutoff point of 30 years of age, by doing so we can check whether the estimated ATT is homogeneous across age.

The apprenticeship contract has a negative effect on the probability of finding a permanent job in the first 15 months. However, the effect is not significantly different from zero and its magnitude is very close to zero. The apprenticeship starts having a sizeable positive effect, although not significant, from the second year since the treatment. The probability of finding a permanent job within the first two years would have been 5 percentage points lower if the apprentice entered the labour market with a temporary job rather than the apprenticeship contract (17.7\% instead of $22.6 \%)$. The positive effect of the apprenticeship becomes larger as time goes by and it turns highly significant from the third year onward. The chances of finding a permanent job within the first three years would have been 23.3 percentage points lower if the apprentice entered the labour market with a temporary job (22.3\% instead of $45.6 \%$ ). Finally, the bottom panel of Table 8 shows that the apprentices close to the cutoff point display estimated ATT which are very similar to those ones of the whole population of apprentices.

\subsection{Robustness Checks}

The estimated parameter of the threshold $s_{1}$ reported in Table 3 shows that there is no discontinuity in the probability of entering a job through an apprenticeship when individuals turn 25-27 years old. The restriction in the set of the available apprenticeship contracts seems therefore not to affect the probability of becoming an apprentice. The discontinuity that drives the identification of the effect is therefore the one at 30 years of age. If the variation in the probability of entering the labour market through an apprenticeship is randomized, then it follows that all the covariates determined prior the realization of the forcing variable should have the same distribution just above and below the cutoff (Lee and Lemieux, 2010). Table 9 reports the tests on the equality of the means just above and below 30 years of age. All observable covariates locally have the same distribution on either side of the discontinuity threshold. This evidence supports the assumption that the cutoff rule generates a randomized experiment.

So far, we have grouped all the temporary workers other than apprentices into only one category. The Italian labour market is however characterized by several types of temporary job arrangements, each one with its own rules and degree of flexibility. In order to check whether the main findings of our study are driven by some particular job contract, we re-estimated the model by keeping in the category of temporary workers only fixed-term employees. More in detail, we delete from the sample employees having job 
Table 8: Estimated probabilities of having already found a permanent job within $t$ months for apprentices

\begin{tabular}{|c|c|c|c|c|c|}
\hline \multirow{2}{*}{ Duration } & $\begin{array}{c}\text { Predicted } \\
\text { probability }^{\dagger}\end{array}$ & $\begin{array}{c}\text { Counterfactual } \\
\text { probability }\end{array}$ & ATT & \multicolumn{2}{|c|}{$\begin{array}{l}95 \% \text { confidence } \\
\text { interval of } \mathrm{ATT}^{\S}\end{array}$} \\
\hline & \multicolumn{5}{|c|}{ All the apprentices } \\
\hline$(0,3]$ months & 0.015 & 0.017 & -0.002 & -0.021 & 0.014 \\
\hline$(3,6]$ months & 0.036 & 0.042 & -0.005 & -0.048 & 0.033 \\
\hline$(6,9]$ months & 0.057 & 0.065 & -0.007 & -0.067 & 0.048 \\
\hline$(9,12]$ months & 0.083 & 0.093 & -0.010 & -0.088 & 0.068 \\
\hline$(12,15]$ months & 0.113 & 0.114 & -0.001 & -0.092 & 0.098 \\
\hline$(15,18]$ months & 0.137 & 0.131 & 0.006 & -0.097 & 0.123 \\
\hline$(18,21]$ months & 0.159 & 0.147 & 0.012 & -0.101 & 0.144 \\
\hline$(21,24]$ months & 0.179 & 0.162 & 0.017 & -0.104 & 0.159 \\
\hline$(24,27]$ months & 0.226 & 0.177 & 0.050 & -0.080 & 0.215 \\
\hline$(27,30]$ months & 0.255 & 0.187 & 0.068 & -0.063 & 0.238 \\
\hline$(30,33]$ months & 0.278 & 0.197 & 0.081 & -0.051 & 0.268 \\
\hline$(33,36]$ months & 0.297 & 0.206 & 0.091 & -0.042 & 0.291 \\
\hline$(36,39]$ months & 0.438 & 0.215 & $0.222 * * *$ & 0.066 & 0.516 \\
\hline \multirow[t]{2}{*}{$(39,42]$ months } & 0.456 & 0.223 & $0.233 * * *$ & 0.078 & 0.506 \\
\hline & \multicolumn{5}{|c|}{29 years old apprentices } \\
\hline$(0,3]$ months & 0.022 & 0.025 & -0.003 & -0.045 & 0.031 \\
\hline$(3,6]$ months & 0.052 & 0.059 & -0.007 & -0.078 & 0.061 \\
\hline$(6,9]$ months & 0.079 & 0.089 & -0.010 & -0.115 & 0.080 \\
\hline$(9,12]$ months & 0.113 & 0.125 & -0.012 & -0.139 & 0.098 \\
\hline$(12,15]$ months & 0.152 & 0.152 & 0.000 & -0.130 & 0.143 \\
\hline$(15,18]$ months & 0.181 & 0.172 & 0.009 & -0.130 & 0.169 \\
\hline$(18,21]$ months & 0.206 & 0.190 & 0.016 & -0.127 & 0.188 \\
\hline$(21,24]$ months & 0.229 & 0.208 & 0.021 & -0.124 & 0.204 \\
\hline$(24,27]$ months & 0.280 & 0.226 & 0.055 & -0.092 & 0.262 \\
\hline$(27,30]$ months & 0.310 & 0.237 & 0.072 & -0.078 & 0.281 \\
\hline$(30,33]$ months & 0.331 & 0.248 & 0.083 & -0.060 & 0.294 \\
\hline$(33,36]$ months & 0.348 & 0.258 & 0.090 & -0.050 & 0.304 \\
\hline$(36,39]$ months & 0.462 & 0.268 & $0.194 * * *$ & 0.035 & 0.512 \\
\hline$(39,42]$ months & 0.486 & 0.276 & $0.210 * * *$ & 0.050 & 0.496 \\
\hline
\end{tabular}

Notes: $* * *$ Significant at $1 \%$.

$\dagger$ This column reports the predicted probability of having already moved to a permanent job within $t$ months from the beginning of the apprenticeship.

\# This column reports the counterfactual probability of having already moved to a permanent job within $t$ months if the apprentice started a temporary job instead of the apprenticeship.

$\S$ The $95 \%$ confidence intervals are computed from the predicted frequencies by sampling 999 times the vector of parameter estimates assuming that the estimator is Normally distributed around the point estimates with a variance-covariance matrix equal to the estimated one. 
Table 9: Tests on the equality of the means of the covariates just below and above the cutoff at 30 years of age

\begin{tabular}{|c|c|c|c|c|c|c|}
\hline & $\begin{array}{c}\text { Mean of } \\
29 \text { years old }\end{array}$ & $\begin{array}{c}\text { Mean of } \\
30 \text { years old }\end{array}$ & $\begin{array}{c}\text { Difference } \\
\text { of the means }\end{array}$ & Std. Err. & $t$-statistic $\S$ & $\begin{array}{c}H_{a}: \text { Difference } \neq 0 \\
p \text {-value }\end{array}$ \\
\hline Female & 0.532 & 0.508 & 0.025 & 0.020 & 1.243 & 0.214 \\
\hline Regional unemployment rate & 0.079 & 0.080 & -0.000 & 0.001 & -0.304 & 0.761 \\
\hline \multicolumn{7}{|l|}{ Education } \\
\hline None or primary & 0.204 & 0.194 & 0.010 & 0.016 & 0.634 & 0.526 \\
\hline Lower secondary & 0.315 & 0.319 & -0.004 & 0.018 & -0.197 & 0.844 \\
\hline Higher secondary & 0.311 & 0.309 & 0.002 & 0.018 & 0.133 & 0.894 \\
\hline University or more & 0.169 & 0.178 & -0.009 & 0.015 & -0.589 & 0.556 \\
\hline \multicolumn{7}{|l|}{ Region } \\
\hline Piemonte-Valle d'Aosta & 0.064 & 0.063 & 0.001 & 0.010 & 0.120 & 0.904 \\
\hline Lombardia & 0.156 & 0.157 & -0.001 & 0.014 & -0.049 & 0.961 \\
\hline Trentino Alto Adige & 0.039 & 0.041 & -0.002 & 0.008 & -0.246 & 0.806 \\
\hline Veneto & 0.066 & 0.057 & 0.010 & 0.010 & 1.023 & 0.306 \\
\hline Friuli Venezia Giulia & 0.018 & 0.018 & -0.000 & 0.005 & -0.046 & 0.963 \\
\hline Liguria & 0.024 & 0.023 & 0.002 & 0.006 & 0.251 & 0.802 \\
\hline Emilia Romagna & 0.089 & 0.109 & -0.020 & 0.012 & -1.675 & 0.094 \\
\hline Toscana & 0.058 & 0.060 & -0.002 & 0.009 & -0.229 & 0.819 \\
\hline Umbria & 0.020 & 0.012 & 0.008 & 0.005 & 1.511 & 0.131 \\
\hline Marche & 0.031 & 0.027 & 0.004 & 0.007 & 0.605 & 0.545 \\
\hline Lazio & 0.119 & 0.110 & 0.009 & 0.013 & 0.714 & 0.475 \\
\hline Abruzzo-Molise & 0.026 & 0.026 & -0.001 & 0.006 & -0.123 & 0.902 \\
\hline Campania & 0.061 & 0.065 & -0.004 & 0.010 & -0.453 & 0.651 \\
\hline Puglia & 0.070 & 0.069 & 0.001 & 0.010 & 0.055 & 0.956 \\
\hline Basilicata-Calabria & 0.058 & 0.053 & 0.005 & 0.009 & 0.534 & 0.593 \\
\hline Sicilia-Sardegna & 0.102 & 0.110 & -0.009 & 0.012 & -0.701 & 0.483 \\
\hline \multicolumn{7}{|l|}{ Nationality } \\
\hline Italian & 0.783 & 0.775 & 0.008 & 0.016 & 0.496 & 0.620 \\
\hline UE & 0.105 & 0.109 & -0.004 & 0.012 & -0.311 & 0.756 \\
\hline Non EU & 0.112 & 0.116 & -0.004 & 0.013 & -0.346 & 0.730 \\
\hline Observations & 1,249 & 1,288 & & & 2,537 & \\
\hline
\end{tabular}

Notes: *** Significant at $1 \%$; * significant at $5 \%$; $*$ significant at $10 \%$

$\S$ The data below and above the cutoff are allowed to have unequal variances and the $t$-statistics are therefore computed using Welch's (1947) formula. 
on projects, jobs on call, or working for a TWA. Table 10 reports the estimation results of the baseline transitions intensities of the single risk and the competing risks model when restricting the control group of temporary workers to fixed-term jobs only. The effect of the apprenticeship contract is very much in line with the ones found in the benchmark model.

Table 10: Estimation results of the baseline hazard function of apprenticeships and fixed-term workers

\begin{tabular}{|c|c|c|c|c|c|c|c|c|c|}
\hline & \multirow{2}{*}{\multicolumn{3}{|c|}{ Single risk model }} & \multicolumn{6}{|c|}{ Competing risks model } \\
\hline & & & & \multicolumn{3}{|c|}{$\begin{array}{c}\text { Transition to permanent job } \\
\text { in the same firm }\end{array}$} & \multicolumn{3}{|c|}{$\begin{array}{l}\text { Transition to permanent job } \\
\text { in a different firm }\end{array}$} \\
\hline & \multicolumn{2}{|l|}{ Coeff. } & \multirow{2}{*}{ Std. Err. } & \multicolumn{2}{|c|}{ Coeff. } & \multirow[t]{2}{*}{ Std. Err. } & \multicolumn{2}{|c|}{ Coeff. } & \multirow[t]{2}{*}{ Std. Err. } \\
\hline \multicolumn{7}{|c|}{ Baseline hazard for fixed-term workers - Reference: $(0,3]$ months } & & & \\
\hline$(3,6]$ months & 0.433 & $* * *$ & 0.065 & 0.654 & $* * *$ & 0.103 & 0.300 & $* * *$ & 0.089 \\
\hline$(6,9]$ months & 0.456 & $* * *$ & 0.067 & 0.527 & $* * *$ & 0.106 & 0.435 & $* * *$ & 0.095 \\
\hline$(9,12]$ months & 0.806 & $* * *$ & 0.068 & 1.224 & $* * *$ & 0.098 & 0.408 & $* * *$ & 0.104 \\
\hline$(12,15]$ months & 0.584 & $* * *$ & 0.075 & 0.530 & $* * *$ & 0.109 & 0.620 & $* * *$ & 0.108 \\
\hline$(15,18]$ months & 0.453 & $* * *$ & 0.082 & 0.305 & $* * *$ & 0.115 & 0.527 & $* * *$ & 0.115 \\
\hline$(18,21]$ months & 0.443 & $* * *$ & 0.086 & 0.239 & $* *$ & 0.117 & 0.524 & $* * *$ & 0.122 \\
\hline$(21,24]$ months & 0.497 & $* * *$ & 0.091 & 0.229 & $* *$ & 0.119 & 0.601 & $* * *$ & 0.125 \\
\hline$(24,27]$ months & 0.505 & $* * *$ & 0.096 & 0.261 & $* *$ & 0.118 & 0.569 & $* * *$ & 0.130 \\
\hline$(27,30]$ months & 0.224 & $* *$ & 0.104 & -0.824 & $* * *$ & 0.155 & 0.605 & $* * *$ & 0.135 \\
\hline$(30,33]$ months & 0.225 & $* *$ & 0.110 & -0.544 & $* * *$ & 0.149 & 0.495 & $* * *$ & 0.145 \\
\hline$(33,36]$ months & 0.231 & $*$ & 0.122 & -0.637 & $* * *$ & 0.178 & 0.482 & $* * *$ & 0.159 \\
\hline more than 36 months & 0.279 & $* *$ & 0.135 & -0.377 & $* *$ & 0.183 & 0.500 & $* * *$ & 0.175 \\
\hline \multicolumn{10}{|c|}{ Variation in the baseline hazard for apprentices } \\
\hline$(0,12]$ months & -0.154 & & 0.529 & 0.484 & $* * *$ & 0.224 & -2.081 & $* * *$ & 0.263 \\
\hline$(12,24]$ months & 0.332 & & 0.552 & 1.297 & $* * *$ & 0.201 & -1.916 & $* * *$ & 0.255 \\
\hline$(24,36]$ months & 1.366 & $* *$ & 0.563 & 3.100 & $* * *$ & 0.185 & -1.699 & $* * *$ & 0.238 \\
\hline more than 36 months & 6.154 & $* * *$ & 0.591 & 8.376 & $* * *$ & 0.330 & -0.911 & $* * *$ & 0.290 \\
\hline Observations & \multicolumn{3}{|c|}{18,617} & \multicolumn{6}{|c|}{18,617} \\
\hline Log-likelihood & \multicolumn{3}{|c|}{$-57,248.5$} & \multicolumn{6}{|c|}{$-60,824.4$} \\
\hline \# of parameters & \multicolumn{3}{|c|}{76} & \multicolumn{6}{|c|}{120} \\
\hline $\operatorname{AIC} / N$ & \multicolumn{3}{|c|}{6.158} & \multicolumn{6}{|c|}{6.547} \\
\hline
\end{tabular}

Notes: *** Significant at $1 \%$; ** significant at $5 \% ; *$ significant at $10 \%$.

Finally, we conduct a sensitivity analysis to check whether the estimation results are robust to the presence of firm or job heterogeneity. We re-estimate the model by augmenting the specification of the hazard function by a set of indicators for the sector, occupation, and working time (part-time and full-time). Table 11 reports the estimation results of the baseline hazard for apprentices and temporary workers. They are in line with those reported in Tables 5 and 6. 
Table 11: Estimation results of the baseline hazard function of the models augmented by firm and job characteristics

\begin{tabular}{|c|c|c|c|c|c|c|c|c|c|}
\hline & \multirow{2}{*}{\multicolumn{3}{|c|}{ Single risk model }} & \multicolumn{6}{|c|}{ Competing risks model } \\
\hline & & & & \multicolumn{3}{|c|}{$\begin{array}{l}\text { Transition to permanent job } \\
\text { in the same firm }\end{array}$} & \multicolumn{3}{|c|}{$\begin{array}{c}\text { Transition to permanent job } \\
\text { in a different firm }\end{array}$} \\
\hline & \multicolumn{2}{|l|}{ Coeff. } & Std. Err. & \multicolumn{2}{|c|}{ Coeff. } & \multirow[t]{2}{*}{ Std. Err. } & \multicolumn{2}{|c|}{ Coeff. } & \multirow[t]{2}{*}{ Std. Err. } \\
\hline \multicolumn{8}{|c|}{ Baseline hazard for temporary workers - Reference: $(0,3]$ months } & & \\
\hline$(3,6]$ months & 0.428 & $* * *$ & 0.061 & 0.626 & $* * *$ & 0.099 & 0.298 & $* * *$ & 0.081 \\
\hline$(6,9]$ months & 0.446 & $* * *$ & 0.063 & 0.533 & $* * *$ & 0.101 & 0.389 & $* * *$ & 0.085 \\
\hline$(9,12]$ months & 0.774 & $* * *$ & 0.062 & 1.174 & $* * *$ & 0.094 & 0.380 & $* * *$ & 0.090 \\
\hline$(12,15]$ months & 0.571 & $* * *$ & 0.067 & 0.558 & $* * *$ & 0.104 & 0.559 & $* * *$ & 0.091 \\
\hline$(15,18]$ months & 0.474 & $* * *$ & 0.071 & 0.332 & $* * *$ & 0.109 & 0.518 & $* * *$ & 0.096 \\
\hline$(18,21]$ months & 0.479 & $* * *$ & 0.074 & 0.261 & $* *$ & 0.111 & 0.542 & $* * *$ & 0.101 \\
\hline$(21,24]$ months & 0.527 & $* * *$ & 0.077 & 0.292 & $* * *$ & 0.112 & 0.583 & $* * *$ & 0.104 \\
\hline$(24,27]$ months & 0.519 & $* * *$ & 0.078 & 0.295 & $* * *$ & 0.113 & 0.561 & $* * *$ & 0.108 \\
\hline$(27,30]$ months & 0.267 & $* * *$ & 0.087 & -0.688 & $* * *$ & 0.142 & 0.584 & $* * *$ & 0.112 \\
\hline$(30,33]$ months & 0.255 & $* * *$ & 0.092 & -0.460 & $* * *$ & 0.140 & 0.473 & $* * *$ & 0.120 \\
\hline$(33,36]$ months & 0.270 & $* *$ & 0.105 & -0.548 & $* * *$ & 0.166 & 0.478 & $* * *$ & 0.133 \\
\hline more than 36 months & 0.302 & $* * *$ & 0.113 & -0.318 & $*$ & 0.167 & 0.475 & $* * *$ & 0.145 \\
\hline \multicolumn{10}{|c|}{ Variation in the baseline hazard for apprentices } \\
\hline$(0,12]$ months & -0.134 & & 0.386 & 0.498 & $* *$ & 0.210 & -2.052 & $* * *$ & 0.249 \\
\hline$(12,24]$ months & 0.369 & & 0.380 & 1.257 & $* * *$ & 0.194 & -1.897 & $* * *$ & 0.233 \\
\hline$(24,36]$ months & 1.421 & $* * *$ & 0.358 & 3.006 & $* * *$ & 0.181 & -1.722 & $* * *$ & 0.221 \\
\hline more than 36 months & 6.240 & $* * *$ & 0.325 & 8.328 & $* * *$ & 0.306 & -0.960 & $* * *$ & 0.273 \\
\hline Observations & \multicolumn{3}{|c|}{22,207} & \multicolumn{6}{|c|}{22,207} \\
\hline Log-likelihood & \multicolumn{3}{|c|}{$-64,733.5$} & \multicolumn{6}{|c|}{$-68,662.8$} \\
\hline \# of parameters & \multicolumn{3}{|c|}{86} & \multicolumn{6}{|c|}{140} \\
\hline $\mathrm{AIC} / N$ & \multicolumn{3}{|c|}{5.838} & \multicolumn{6}{|c|}{6.197} \\
\hline
\end{tabular}

Notes: *** Significant at $1 \%$; ** significant at $5 \%$; significant at $10 \%$. 


\section{Conclusions}

In view of the current economic situation and the high level of youth unemployment in Italy, in the last years the policy maker has been increasingly looking at the apprenticeship as one of the main channels of labour market entry for youth. This renewed interest in the apprenticeship as a port of entry into regular employment took shape with some recent labour market reforms which have made easier its use of apprenticeships and defined it as a job relationship with the special aim of fostering human capital.

This article is therefore aimed at understanding whether apprenticeships are effective pathways into permanent jobs compared to other forms of temporary jobs in Italy. The theory does not provide clearcut predictions about the possible effect of performing an apprenticeship experience compared to other forms of temporary jobs in terms of future employability. On the one hand, since apprentices are cheap labour force because of lower wages and lower labour taxes paid by firms, the employers might use the apprenticeship only as a way of facing the economic crisis and the rising international competition. On the other hand, hiring low-skilled workers and provide them with training during the apprenticeship might be a long term investment and a way of screening the best candidates before being locked into an open-ended job relationship. The main contribution of this paper consists in shedding light on whether the institution of apprenticeship is an effective way of increasing the incentives of firms to invest in the human capital of low-skilled workers and/or revealing information about the job candidates and, thereby, rising the employability of the apprentices with respect to that of other temporary workers.

From an administrative dataset covering all the job relationships started in Italy between the beginning of 2009 and the mid of 2012, we select a sample of more than 22, 000 young Italian workers starting a temporary job in 2009. We follow them over time until they enter a permanent job and estimate their hazard rate of entering a permanent job by splitting them in apprentices and other types of temporary workers. We can argue that, conditional on observed and unobserved characteristics, if the apprentices are more (less) likely to get a permanent job than other types of temporary workers, then apprentices might have received more (less) training, accumulated more (less) human capital, and become more (less) likely a firm asset than other temporary workers.

Individuals might select themselves into temporary jobs or apprenticeships on the basis of individuals' unobservables and firms might select workers into different types of contracts according to firm unobservables. Since both types of unobserved heterogeneity might be related to the time until the worker is able to find a permanent job, the variable for the type of contract is endogenous. We take it into account in a quasi-experiment 
setting: identification is based on the discontinuity in the propensity to be hired as an apprentice with respect to age at some cutoff points. The institutional setting imposes that individuals can be hired as apprentices if they are younger than 29 years and 364 days. There also some particular forms of apprenticeship which are only allowed until 24 years and 364 days of age; this age threshold is set to 26 years and 364 days in Campania, Puglia, Basilicata, Calabria, Sicilia, and Sardegna because of the state of the labour market in these regions. Selection on unobservables is therefore faced by estimating hazard functions towards permanent jobs by contract type in a fuzzy regression discontinuity setting.

We find that from the third year since the sample entry, apprentices show a hazard function towards permanent jobs significantly higher than that of temporary workers. We propose two explanations of our findings. First, as firms are legally obliged to provide their apprentices with training, the apprentices might accumulate more human capital than temporary workers and, thereby, they might be more likely to get a permanent job once the apprenticeship period expires. Second, the apprenticeship system might be more effective in screening job candidates than other forms of temporary workers, since training tests workers' skills and releases thereby private information about workers' ability and motivations. Once the apprenticeship has expired, the employer can decide whether to get locked into an open-ended job relationship with high firing costs on the basis of a richer and more complete information than that of temporary workers.

By estimating a competing risks model which distinguishes a transition to a permanent job within the same firm providing the treatment from the one to a different firm, we find that: i) apprentices are more likely to find a permanent job within the same firm; ii) apprentices are always more likely than temporary workers to enter a permanent job within the same firm; iii) temporary workers are instead more likely than apprentices to find a permanent job in a different firm. The specificity of the human capital accumulation and the private nature of the information on workers' ability released by training might explain the first finding. Apprentices accumulating more firm specific human capital and temporary workers accumulating more general skills might instead explaining the other findings.

We conclude therefore that apprenticeships are more effective than other forms of temporary contracts in leading workers to a stable job relationship, especially within the same firm. Our findings need however to be qualified for a number of reasons. First, we identify the effect of the type of contract around the threshold age of 30. As such, we can extend the policy suggestions to school-leavers, only if we can credibly assume that 
the identified local effect holds also for younger people. Second, the time horizon we observe is restricted and it would be helpful to have a longer term evaluation of the effect of the apprenticeship on the future employability, especially because many apprenticeship contracts are three years long. Third, as we do not have information on firms' and workers' training activities, we cannot disentangle the contribution of the specific and/or general human capital accumulation from the contribution of the screening hypothesis in determining our empirical findings. Different policy advices might be proposed depending on whether the dominant contribution is the former or the latter. If the human capital accumulation were the main force leading our results, then policies like further labour tax reduction, stricter monitoring to verity that firms actually comply with the legal training requirements, and the creation of a system for the certification of skills acquired during the apprenticeship period ${ }^{20}$ could be of help in developing a well-established path towards permanent jobs. If apprenticeships were effective mainly because of workers' screening, this would mean that firms largely value the assessment of workers' skills before locking themselves into an open-ended relationship. Then, it might be the hint that the employment protection legislation of permanent workers is too strict and that forms of workers' screening are needed also in other types of job arrangements.

\section{Appendix}

\section{A The simulation algorithm with regard to the goodness-of-fit}

The simulation algorithm with regard to the goodness-of-fit proceeds according to the following steps:

1. Draw a vector of parameter estimates $\widehat{\Theta}$ assuming normality around the point estimates with a variance-covariance matrix equal to the estimated one. This ensures that the Monte Carlo confidence intervals encompass the parameter estimation precision.

\footnotetext{
${ }^{20}$ There is a debate on whether training certification could discourage firm-provided training (Acemoglu and Pischke, 2000). If the general component of the skills acquired by workers in a job relationship becomes indeed common knowledge, the expected duration of the job relationship decreases and the employer has less time to recoup the cost of training. However, certification would increase the effort exerted by the worker as it ensures that she receives more of the return to their general training. Acemoglu and Pischke (2000) claim that the removal of the institutions that certify apprenticeship skills in Germany would not increase firm-sponsored training, but likely undermine the whole German apprenticeship system.
} 
2. Assign to each individual the observed explanatory variables and a vector of unobserved characteristics drawn with probabilities given by Eq. (6).

3. Simulate the contract type by a lottery based on the predicted probability of entering the sample through an apprenticeship. More in detail, for $i=1, \ldots, N$ we draw $\eta_{i}$ from a standard uniform distribution. If

$$
\frac{\exp \left[\mathbf{x}_{i} \widehat{\boldsymbol{\beta}}_{a}+\widehat{\alpha}_{1} s_{i 1}+\widehat{\alpha}_{2} s_{i 2}+\widehat{f\left(a g e_{i}\right)}+\widehat{v}_{i a}\right]}{\left.1+\exp \left[\mathbf{x}_{i} \widehat{\boldsymbol{\beta}}_{a}+\widehat{\alpha}_{1} s_{i 1}+\widehat{\alpha}_{2} s_{i 2}+\widehat{f\left(a g e_{i}\right.}\right)+\widehat{v}_{i a}\right]} \leq \eta_{i},
$$

individual $i$ obtains an apprenticeship. Otherwise, (s)he enters the sample with a temporary job.

4. Simulate the transition to a permanent job by a sequence of quarterly transition lotteries starting from the moment of sample entry. These transition lotteries are based on the empirical counterparts of the instantaneous probability of moving to a permanent job, conditional on surviving until that moment. Their form is derived by Eq. (4). The simulation procedure is halted once the end of the observation period is reached, i.e. in June 2012, 10 to 14 quarters after the sampling date.

5. Repeat steps 1 to $4 R=999$ times to get $R$ independent realizations and build Monte Carlo confidence intervals.

\section{References}

Acemoglu, D. and J.S. Pischke, "Why do firms train? Theory and evidence," The Quarterly Journal of Economics, 1998, 113 (1), 78-118.

_ and _ , "Certification of training and training outcomes," European Economic Review, 2000, 44 (4-6), 917-927.

Amuedo-Dorantes, C., M.A. Malo, and F. Muñoz-Bullón, "The role of temporary help agency employment on temp-to-perm transitions," Journal of Labor Research, 2009, 29 (2), 138-161.

Askilden, J.E. and Ø.A. Nilsen, "Apprentices and young workers: A study of the Norwegian youth labour market," Scottish Journal of Political Economy, 2005, 52 (1), 1-17. 
Autor, D.H., "Why do temporary help firms provide free general skills training?," Quarterly Journal of Economics, 2001, 116 (4), 1409-1448.

Berton, F., F. Devicienti, and L. Pacelli, "Are temporary jobs a port of entry into permanent employment? Evidence from matched employer-employee data," International Journal of Manpower, 2011, 32 (8), 879-899.

Boockmann, B. and T. Hagen, "Fixed-term contracts as sorting mechanisms: Evidence from job durations in West Germany," Labour Economics, 2008, 15 (5), 984-1005.

Booth, A. L and S.E. Satchell, "Apprenticeships and job tenure: A competing risks model with time-varying covariates," CEPR Discussion Papers 762, CEPR Discussion Papers 1993.

Booth, A.L., J.J. Dolado, and J. Frank, "Symposium on temporary work," Economic Journal, 2002, 112 (480), F181-F188.

_, M. Francesconi, and J. Frank, "Temporary jobs: Stepping stones or dead ends?," Economic Journal, 2002, 112 (480), F189-F213.

Bosio, G., "Duration dependence in the exit from a temporary job: Does contract type matter?," Politica economica, 2011, (1), 49-82.

Cappellari, L., C. Dell'Aringa, and M. Leonardi, “Temporary employment, job flows and productivity: A tale of two reforms," IZA Discussion Papers 6526, Institute for the Study of Labor (IZA) 2012.

Casquel, E. and A. Cunyat, "Temporary contracts, employment protection and skill: A simple model," Economics Letters, 2008, 100 (3), 333-336.

Clark, D. and R. Fahr, "The promise of workplace training for non-college bound youth: Theory and evidence from German apprenticeship," CEP Discussion Papers dp0518, Centre for Economic Performance, LSE 2002.

Cockx, Bart and Matteo Picchio, "Are short-lived jobs stepping stones to long-lasting jobs?," Oxford Bulletin of Economics and Statistics, 2012, 74 (5), 646-675.

de Graaf-Zijl, M., "The economic and social consequences of temporary employment: A review of the literature," SEO Discussion Papers 47, SEO Institute 2005. 
_ , G. van den Berg, and A. Heyma, "Stepping stones for the unemployed: the effect of temporary jobs on the duration until (regular) work," Journal of Population Economics, 2011, 24 (1), 107-139.

Faccini, R., "Reassessing labour market reforms: Temporary contracts as a screening device," Economic Journal, 2013, forthcoming.

Gambin, L., C. Hasluck, T. Hogarth, P. Ryan, and P. Elias, "Options study for the long-term evaluation of apprenticeships," BIS research paper 56, BIS; Department for Business Innovation and Skill 2011.

Gaure, S., K. Røed, and T. Zhang, "Time and causality: A Monte Carlo assessment of the timing-of-events approach," Journal of Econometrics, 2007, 141 (2), 1159-1195.

Göbel, C. and E. Verhofstadt, "Is temporary employment a stepping stone for unemployed school leavers?," Technical Report 2008.

Hagen, T., "Do fixed-term contracts increase the long-term employment opportunities of the unemployed?," Technical Report 2003.

Hahn, J., P. Todd, and W. Van der Klaauw, "Identification and estimation of treatment effects with a regression-discontinuity design," Econometrica, 2001, 69 (1), 201-09.

Hartman, L., L. Liljeberg, and O. Nordström Skans, "Stepping-stones, dead-end, or both? An analysis of Swedish replacement contracts," Empirical Economics, 2010, 38 (3), 645-668.

Heckman, J.J. and B. Singer, "A method for minimizing the impact of distributional assumptions in econometric models for duration data," Econometrica, 1984, 52 (2), 271-320.

Ichino, A., F. Mealli, and T. Nannicini, "From temporary help jobs to permanent employment: What can we learn from matching estimators and their sensitivity?," Journal of Applied Econometrics, 2008, 23 (3), 305-327.

Lancaster, T., The Econometric Analysis of Transition Data, Cambridge, UK: Cambridge University Press, 1992.

Lee, D.S. and T. Lemieux, "Regression discontinuity designs in economics," Journal of Economic Literature, 2010, 48 (2), 281-355. 
Lilla, M. and S. Staffolani, "Young entrants, temporary jobs and career opportunities: Short-term perspectives of young Italian workers," Rivista di statistica ufficiale, 2012, 14 (1), 50-60.

OECD, “The OECD Job Study: Implementing the Strategy,” Technical Report 1996.

OECD, Employment Outlook, Paris: OECD, 2004.

Picchio, M., "Temporary contracts and transitions to stable jobs in Italy," Labour, 2008, 22 (s1), 147-174.

Salant, S.W., "Search theory and duration data: A theory of sorts," The Quarterly Journal of Economics, 1977, 91 (1), 39-57.

van der Klaauw, W., "Estimating the effect of financial aid offers on college enrollment: A regression-discontinuity approach," International Economic Review, 2002, 43 (4), 1249-1287.

Welch, B.L., "The generalization of 'student's' problem when several different population variances are involved," Biometrika, 1947, 34 (1-2), 28-35. 